\title{
Heterochrony, modularity, and the functional evolution of the mechanosensory lateral line canal system of fishes
}

\author{
Nathan C Bird and Jacqueline F Webb*
}

\begin{abstract}
Background: The canals of the mechanosensory lateral line system are components of the dermatocranium, and demonstrate phenotypic variation in bony fishes. Widened lateral line canals evolved convergently in a limited number of families of teleost fishes and it had been hypothesized that they evolved from narrow canals via heterochrony and explore modularity in the lateral line system. Two species of cichlids with different canal phenotypes were used to test a hypothesis of heterochrony. Histological material prepared from ontogenetic series of Aulonocara stuartgranti (widened canals) and Tramitichromis sp. (narrow canals) was analyzed using ANCOVA to determine rates of increase in canal diameter and neuromast size (length, width) and to compare the timing of onset of critical stages in canal morphogenesis (enclosure, ossification).

Results: A faster rate of increase in canal diameter and neuromast width (but not length), and a delay in onset of canal morphogenesis were found in Aulonocara relative to Tramitichromis. However, rates of increase in canal diameter and neuromast size among canals, among canal portions and among canals segments reveal similar trends within both species.

Conclusion: The evolution of widened lateral line canals is the result of dissociated heterochrony - acceleration in the rate of increase of both canal diameter and neuromast size, and delay in the onset of canal morphogenesis, in Aulonocara (widened canals) relative to Tramitichromis (narrow canals). Common rates of increase in canal diameter and neuromast size among canal portions in different dermatocranial bones and among canal segments reflect the absence of local heterochronies, and suggest modular integration among canals in each species. Thus, canal and neuromast morphology are more strongly influenced by their identities as features of the lateral line system than by the attributes of the dermatocranial bones in which the canals are found. Rate heterochrony manifested during the larval stage ensures that the widened canal phenotype, known to be associated with benthic prey detection in adult Aulonocara, is already present before feeding commences. Heterochrony can likely explain the convergent evolution of widened lateral line canals among diverse taxa. The lateral line system provides a valuable context for novel analyses of the relationship between developmental processes and the evolution of behaviorally and ecologically relevant phenotypes in fishes.
\end{abstract}

Keywords: Aulonocara, Tramitichromis, Cichlidae, Neuromast, Dermatocranium, Heterochrony, Modularity, Lateral line

\footnotetext{
* Correspondence: jacqueline_webb@mail.uri.edu

Current address: Department of Biological Sciences, University of Rhode Island, 120 Flagg Road, Kingston RI 02881, USA
} 


\section{Background}

Heterochrony, evolutionary change in developmental rate or relative timing of developmental events, plays a key role in the transformation of morphology in evolutionary time [1-5] and can play an important role in both the origin and evolutionary diversification of complex phenotypes $[6,7]$. Heterochrony may occur at the level of the whole organism, or among phenotypic elements (thus defined as local [3] or regional [8] heterochrony) resulting in novel phenotypes [9-11]. Heterochronic change among phenotypic elements may also occur as the result of a combination of both increases (peramorphosis) and decreases (paedomorphosis) in developmental rates or temporal displacements in the onset and/or offset of developmental events among different phenotypic elements [2]. Such a combination of heterochronic shifts has been described as "dissociated heterochrony" [12] or "mosaic heterochrony" [13]. In vertebrates, heterochrony has been identified as an important aspect of the evolution of the skull of fishes, for example, [14-16], amphibians, for example, [17-19], reptiles, for example, [20], birds, for example, [21] and mammals, for example, [22-26].

The mechanosensory lateral line system is a primitive vertebrate sensory system found in all fishes and in larval and aquatic adult amphibians. In bony fishes it consists of neuromast receptor organs located on the skin and in pored lateral line canals on the head and trunk, reviewed in [27]. On the head, the lateral line canals are embedded within an evolutionarily conserved subset of dermatocranial bones (Figure 1). The supraorbital canal (SO) is contained in the tubular nasal bone, which sits in soft tissue medial to the olfactory sac, and the frontal bone, which forms part of the neurocranial roof and the dorsal edge of the orbit. The infraorbital canal (IO) is found within the series of infraorbital bones (including the lacrimal bone), which border the ventral half of the orbit. The preopercular canal (PO) is found in the preopercular bone, part of the mobile opercular apparatus, which plays an important role in the generation of water flows critical for gill ventilation and feeding. The mandibular canal (MD) is contained within the two bones that compose the lower jaw - the tooth-bearing dentary bone and the anguloarticular bone. The lumen of the MD canal is contiguous with the lumen of the PO canal. The SO, IO and PO canals typically meet just caudal to the eye, continuing caudally as the otic and post-otic canals in the pterotic and extrascapular bones. The post-otic canal continues through the post-temporal and supracleithral bones before continuing into the trunk canal, which is contained within the tubed lateral line scales.

Canal neuromasts are found in stereotyped locations within individual canal segments that compose a canal, a pattern that is the result of neuromast-centered canal morphogenesis [30]. Morphogenesis of individual canal segments occurs in four stages (Figure 2A, Stages I-IV, $[29,31]$ ). After differentiation within the epithelium (Stage I) a presumptive canal neuromast sinks into a depression (Stage IIa) and canal walls ossify within the dermis on either side of it (Stage IIb). Next, soft tissue fuses over the neuromast forming a canal segment (Stage III), and, finally, the ossified canal walls extend over the neuromast within the dermis and fuse to form the ossified roof of the canal segment (Stage IV). Adjacent canal segments grow toward one another (Figure 2B,C) and fuse (Figure 2D) leaving a pore between them (Figure 2E), as canal segments become incorporated into underlying dermal bone [32].

Despite the common structural and developmental themes that define canal morphogenesis, several phenotypic variations are found among bony fishes. Five cranial lateral line canal phenotypes are defined - three variations on narrow canals (narrow-simple, narrow-branched, narrow with widened tubules), reduced canals and widened canals [27]. A narrow-simple ("narrow" hereafter) canal phenotype is the most common, and is probably the ancestral condition for bony fishes [27,33]. Narrow-branched and reduced canals have been proposed as the result of positive and negative heterochronic shifts from an ancestral narrow canal phenotype, respectively [33]. Widened canals have also evolved from narrow canals, and are particularly intriguing. They are characterized by a large canal diameter and large canal neuromasts, but also by weak canal roof ossification and large canal pores (presumably the result of a delay or truncation in ossification of the canal roof), suggesting evolution via dissociated heterochrony. Narrow-simple and widened canals are also functionally distinct $[34,35]$. Widened canals are critical for prey detection [36,37], which provides an important context for understanding of the functional evolution of lateral line canal phenotype.

A test of heterochrony to explain the evolution of widened canals requires the quantitative analysis of the development of closely related species with narrow and widened canal phenotypes. Unfortunately, most fishes with widened canals are inaccessible for study or are particularly difficult to rear in the laboratory [27,38], and pairs of closely related species with narrow and widened canals that are amenable to laboratory study are difficult to identify. However, the speciose African cichlid fishes present unique opportunities for such an analysis. The cranial lateral line canal system of cichlids has been noted in major monographs and taxonomic synopses that describe their cranial osteology [39-41]. Most cichlids have narrow lateral line canals $[29,42-44]$, but a few genera endemic to Lake Tanganyika and Lake Malawi have widened lateral line canals $[39,45,46]$. A recent comparison of the development of the SO and MD lateral line canals in the Lake Malawi cichlids, Labeotropheus fuelleborni and Metriaclima zebra, both mbuna (rock dwelling) species 


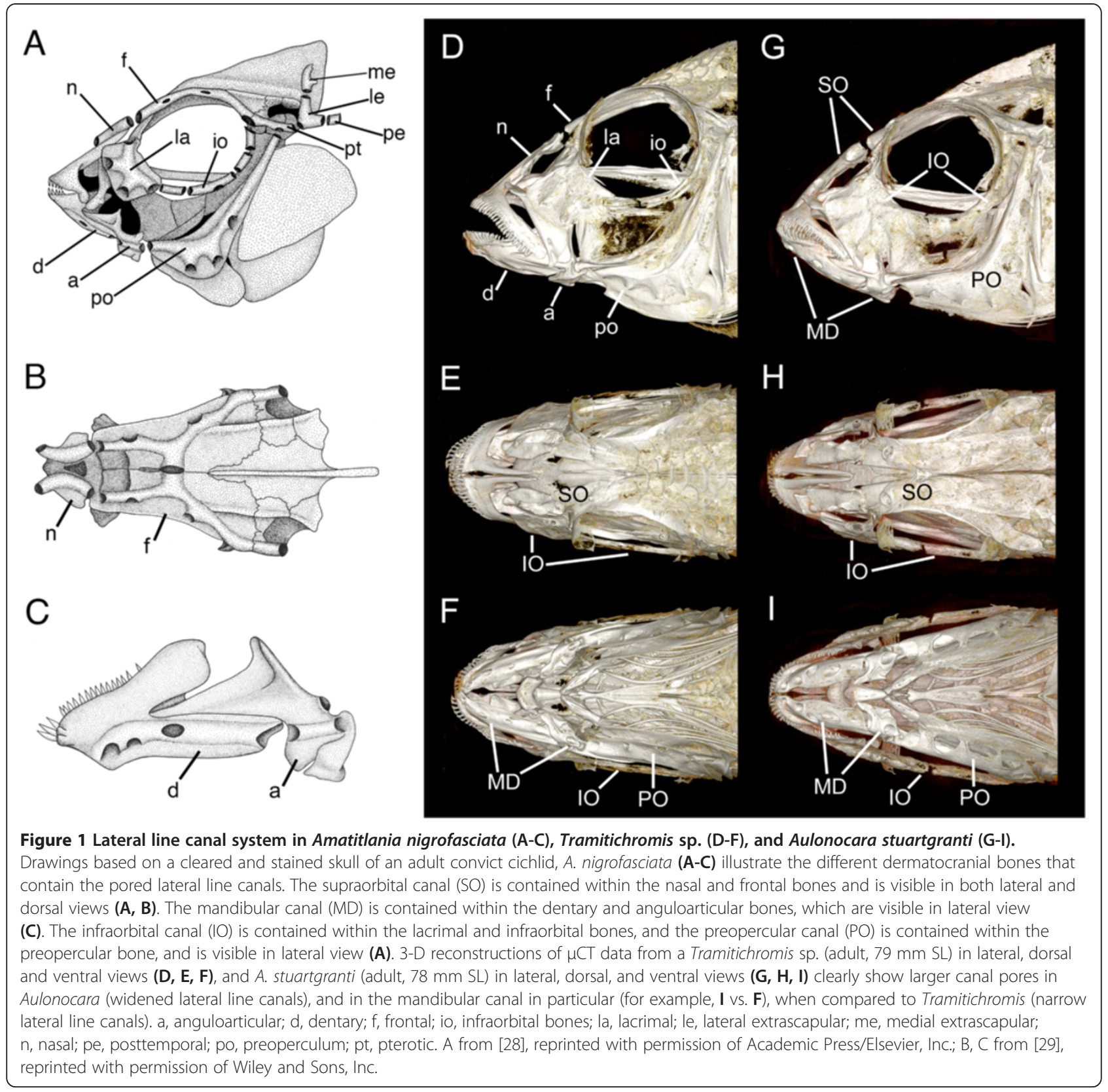

with narrow canals, and Aulonocara baenschi, a nonmbuna (sand dwelling) species with widened canals, demonstrated that differences in the rate of increase in canal diameter and canal neuromast size can explain the evolution of the widened canal phenotype [47].

This study will use a quantitative analysis of the development of the cranial lateral line canals and canal neuromasts in two closely related sand dwelling (non-mbuna) Lake Malawi cichlids - Aulonocara stuartgranti (widened canals) and Tramitichromis sp. (narrow canals). Analysis of covariance (ANCOVA) will be used to detect heterochrony in rates of increase in canal diameter and neuromast size (length, width) at the level of the lateral line canal system
(SO and MD canals combined), individual canals (SO, MD canals), canal portions in different dermal bones, and individual canal segments in each of the canals. It will then consider how local heterochronies within a species (differences in developmental rates between canals, canal portions, canal segments) reveal independence among modules in the lateral line canal system. It had been shown previously that the two experimental species used here both feed on benthic invertebrate prey in sandy substrates, but use different prey detection strategies $[36,37,48]$. Thus, this analysis will, for the first time, put heterochrony in the evolution of adaptive phenotypes in the lateral line system in both behavioral and ecological context. 


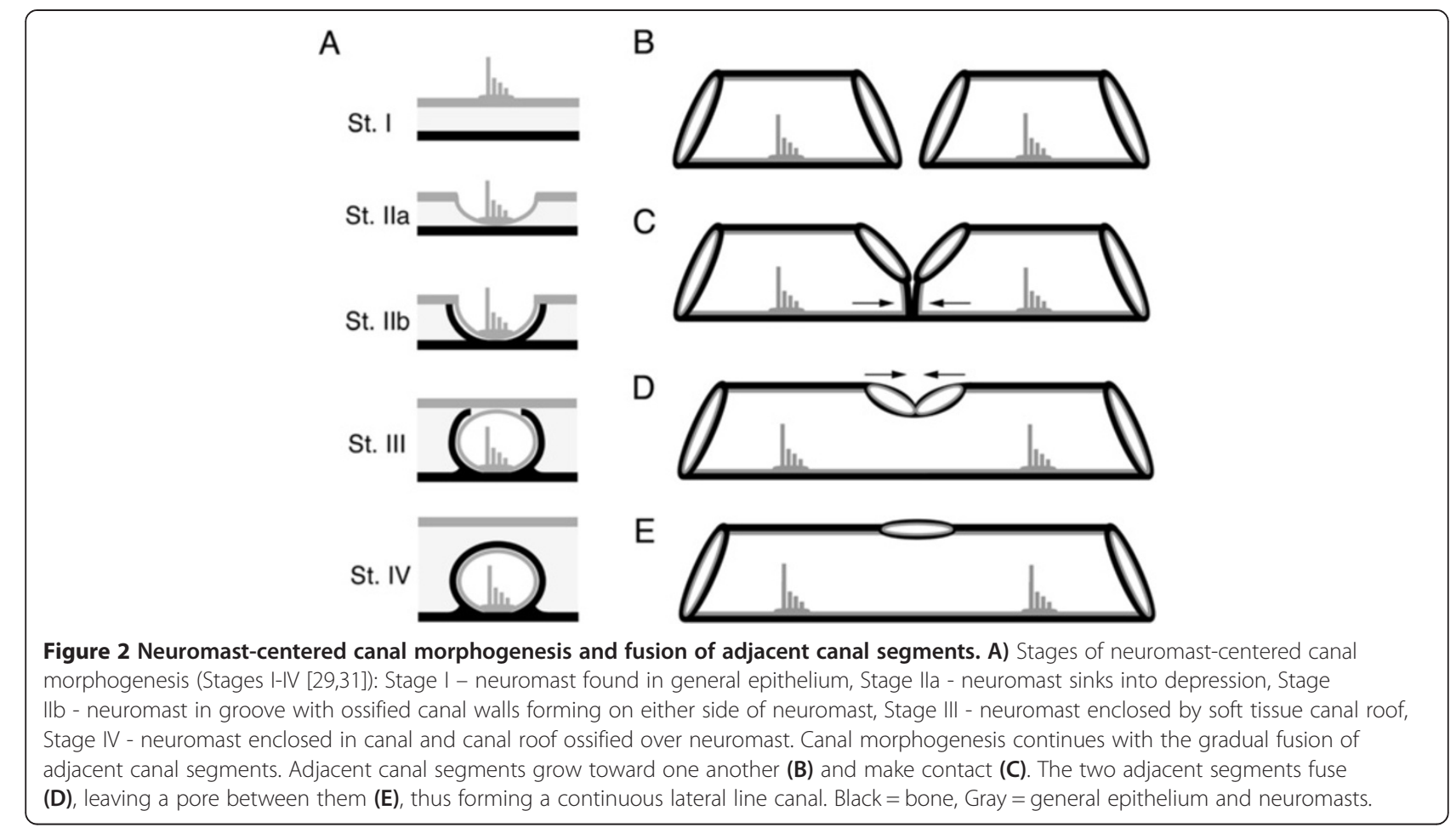

\section{Methods}

Two species of sand dwelling Lake Malawi cichlids, Tramitichromis sp. and Aulonocara stuartgranti (referred to by genus throughout), were obtained from Old World Exotic Fish, Inc., (Homestead, FL, USA) or Live Fish Direct (Draper, UT, USA; Tramitichromis) and from Bluegrass Aquatics (Louisville, KY, USA; Aulonocara). Groups of adults (one male with several females) were maintained in $190 \mathrm{~L}$ aquaria in flow-through systems with appropriate mechanical and biological filtration at $80 \pm 2^{\circ} \mathrm{F}$ with $1.0 \pm$ 0.2 ppt salinity (Cichlid Lake Salt, Seachem Laboratories, Inc., Madison, GA, USA) and a 12:12 light cycle. Fish were fed commercial pellet food (New Life Spectrum Cichlid Formula, New Life International, Homestead, FL, USA) one to two times daily. Several days after a brood was noticed (female with expanded buccal cavity), newly hatched fry were removed from the mouth of brooding females and maintained in round-bottom flasks submerged in small tanks and supplied with constant water flow in an AHAB multi-tank flow through system (Aquatic Habitats Inc., Apopka, FL, USA). After yolk absorption, freeswimming fry were allowed to swim out of the flasks into the small tanks and were fed plankton pellets (Hikari ${ }^{\circ}$ Middle Larval Stage Plankton), then flake food (equal parts egg yolk, earthworm, and Spirulina flakes, Pentair Aquatic Eco-Systems, Inc., Apopka, FL, USA). Aulonocara from two broods (AuHb-B017 and AuHb-B021) were sampled every two to three days (6 to 61 days post-fertilization (dpf) and 6 to $112 \mathrm{dpf}$, respectively) and Tramitichromis from a single brood (TRA-B002) were sampled every two to three days ( 5 to 55 days $\mathrm{dpf}$ ) to generate ontogenetic series for histological analysis (Figure 3). Fish were anesthetized with MS 222 (ethyl 3-aminobenzoate methanesulfonate; SigmaAldrich Co. LLC, St. Louis, Missouri, USA) and fixed in

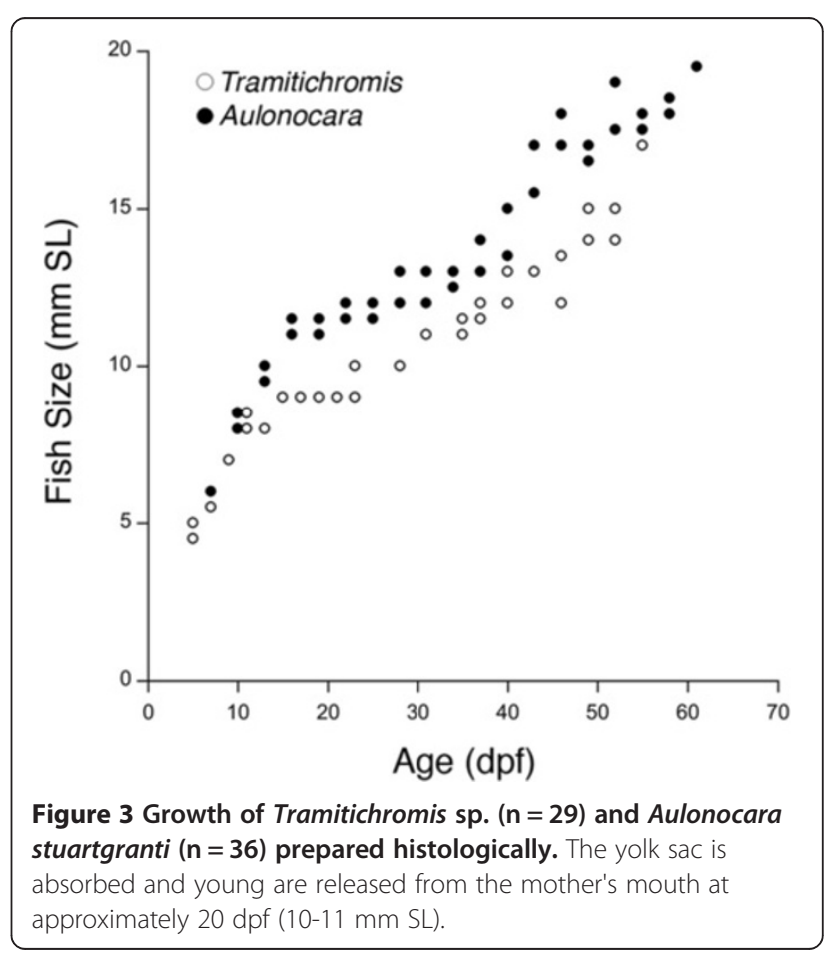


10\% formalin (Sigma F75F) in PBS (phosphate buffered saline, Sigma \#P3744), following an approved IACUC protocol.

\section{Analysis of canal and neuromast development}

Histological material was prepared from ontogenetic series of Aulonocara stuartgranti ( $\mathrm{n}=25,7$ to $61 \mathrm{dpf}, 6$ to $19.5 \mathrm{~mm} \mathrm{SL})$ and Tramitichromis sp. ( $\mathrm{n}=20,5$ to $17 \mathrm{~mm}$ $\mathrm{SL}, 5$ to $55 \mathrm{dpf}$ ). Fish $>6 \mathrm{~mm} \mathrm{SL}$ were decalcified in Cal-Ex Decalcifier (Thermo Fisher Scientific, Waltham, Massachusetts, USA) for two hours (6 to $7.5 \mathrm{~mm} \mathrm{SL}$ ), 3.5 hours ( 8 to $8.5 \mathrm{~mm}$ ), or seven to eight hours $(>8.5 \mathrm{~mm}$ $\mathrm{SL}$ ), dehydrated in an ascending ethanol and t-butyl alcohol series, and embedded in Paraplast (Thermo Fisher Scientific, Waltham, Massachusetts, USA). Serial transverse sections were cut at $8 \mu \mathrm{m}$, mounted on slides subbed with $10 \%$ albumin in $0.9 \% \mathrm{NaCl}$, and stained with a modified HBQ stain [49].

Analyses of the development of a representative subset of the cranial lateral line canals - the supraorbital (SO) and mandibular (MD) canals and their canal neuromasts (Figures 1 and 4) - were completed in both species. These two canals run rostro-caudally and allow accurate measurements of canal and neuromast dimensions in serial crosssections. The study of cleared and stained material, $\mu \mathrm{CT}$ images and dried skeletons indicate that these two canals are good representatives of the entire cranial lateral line canal system. Staging of canal development followed the scheme defined by [29] for another cichlid, Amatitlania nigrofasciata (=Archocentrus nigrofasciatus). Developmental stage (Stage I to IV) was recorded and presence/absence of canal neuromasts was noted in every section allowing the identification of all five canal neuromasts (SO1 to 5,
MD1 to 5, Figure 4) and the stage of canal segment development (I-IV) at the location of each neuromast.

Neuromast length was determined for each of the five $\mathrm{SO}$ and MD neuromasts in both the right and left canals by counting the number of sections in which neuromast tissue (hair cells and thickened epithelium composed of mantle cells) was present and multiplying the result by section thickness $(8 \mu \mathrm{m}$, measurement error $\pm 16 \mu \mathrm{m})$. Neuromast width was measured (to the nearest $0.1 \mu \mathrm{m}$ ) at the rostro-caudal midpoint of each canal neuromast by digitally tracing the curve defined by the apical surface of the cells composing the neuromast. Internal canal diameter (defined by surface of ossified canal bone) was measured (to nearest $0.1 \mu \mathrm{m}$ ) in the same section as neuromast width at the point above the neuromast with maximum diameter. Canal diameter could only be measured after canal morphogenesis had commenced, and was thus determined only in those canal segments at Stages II-IV. All measurements were obtained digitally using Spot software (v. 5.0, Diagnostic Instruments, Sterling Heights, MI, USA) on an Olympus BH-2 compound microscope (Olympus America, Center Valley, Pennsylvania, USA) or Zeiss AxioVision software (v 4.6.3) on a Zeiss AxioImager1 compound microscope (Carl Zeiss MicroImaging $\mathrm{GmbH}$, Gottingen, Germany).

Additional ontogenetic series of Tramitichromis $(\mathrm{n}=15$, 13 to $52 \mathrm{dpf}, 8$ to $14 \mathrm{~mm} \mathrm{SL}$ ) and Aulonocara ( $\mathrm{n}=12,7$ to $112 \mathrm{dpf}, 5.5$ to $22 \mathrm{~mm} \mathrm{SL}$ ) were enzymatically cleared and stained for cartilage and bone [50] to visualize the overall timing of bone ossification and canal morphogenesis (Stages I-IV) for comparison with histological data. Images of cleared and stained specimens were captured using Spot software (v. 5.0) on a Nikon SMZ1500 dissecting

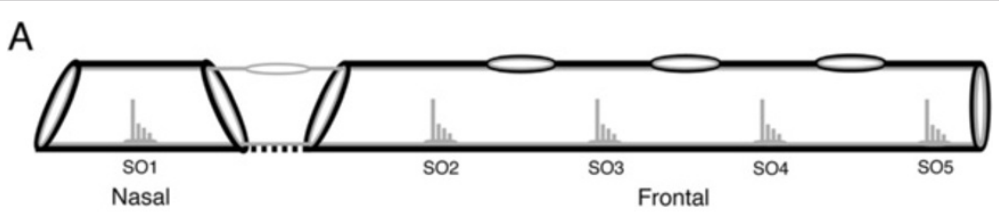

B

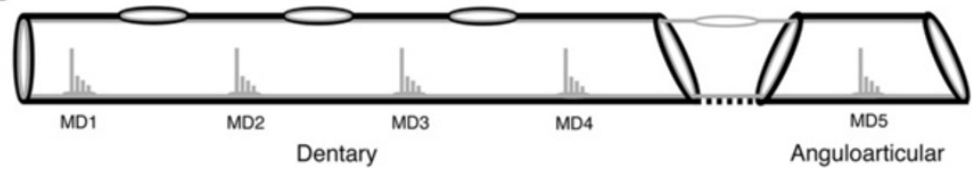

Figure 4 Distribution of canal neuromasts in the dermatocranial bones containing supraorbital and mandibular lateral line canals. Schematic representation of the morphology of the supraorbital (A) and mandibular (B) canals as used for the evaluation of the modular organization of the cranial lateral line canal system. A) Five canal neuromasts are contained within the supraorbital canal, which is composed of canal portions in the nasal (SO1) and frontal (SO2 to SO5) bones including five canal segments (SO1 to SO5). B) Five canal neuromasts are contained within the mandibular canal, which is composed of canal portions in the dentary (MD1 to MD4) and anguloarticular (MD5) bones including five canal segments (MD1 to MD5). Black= bone, Gray= general epithelium and neuromasts. Note that pores are located between canal segments (see Figure 2), and that bone is lacking between portions at the articulation of adjacent dermatocranial bones. 
microscope (Nikon Instruments Inc., Melville, New York, USA).

\section{Statistical analyses}

The rates of increase in three variables - canal diameter and neuromast size (length, width) - in the SO and MD canals (combined) were calculated in Tramitichromis and Aulonocara. Analysis of covariance (ANCOVA) was used to detect differences in rates of increase in canal diameter and neuromast size between species to test a hypothesis of heterochrony. Then, in a second set of ANCOVA's, rates of increase were compared between species for canals, between canal portions within each canal, and among the five canal segments in each canal, in order to detect local heterochronies (Figure 5A). Left-right mean for each variable was calculated and used in all analyses in order to compensate for asymmetry due to variation in sectioning angle among individuals. All data were found to be

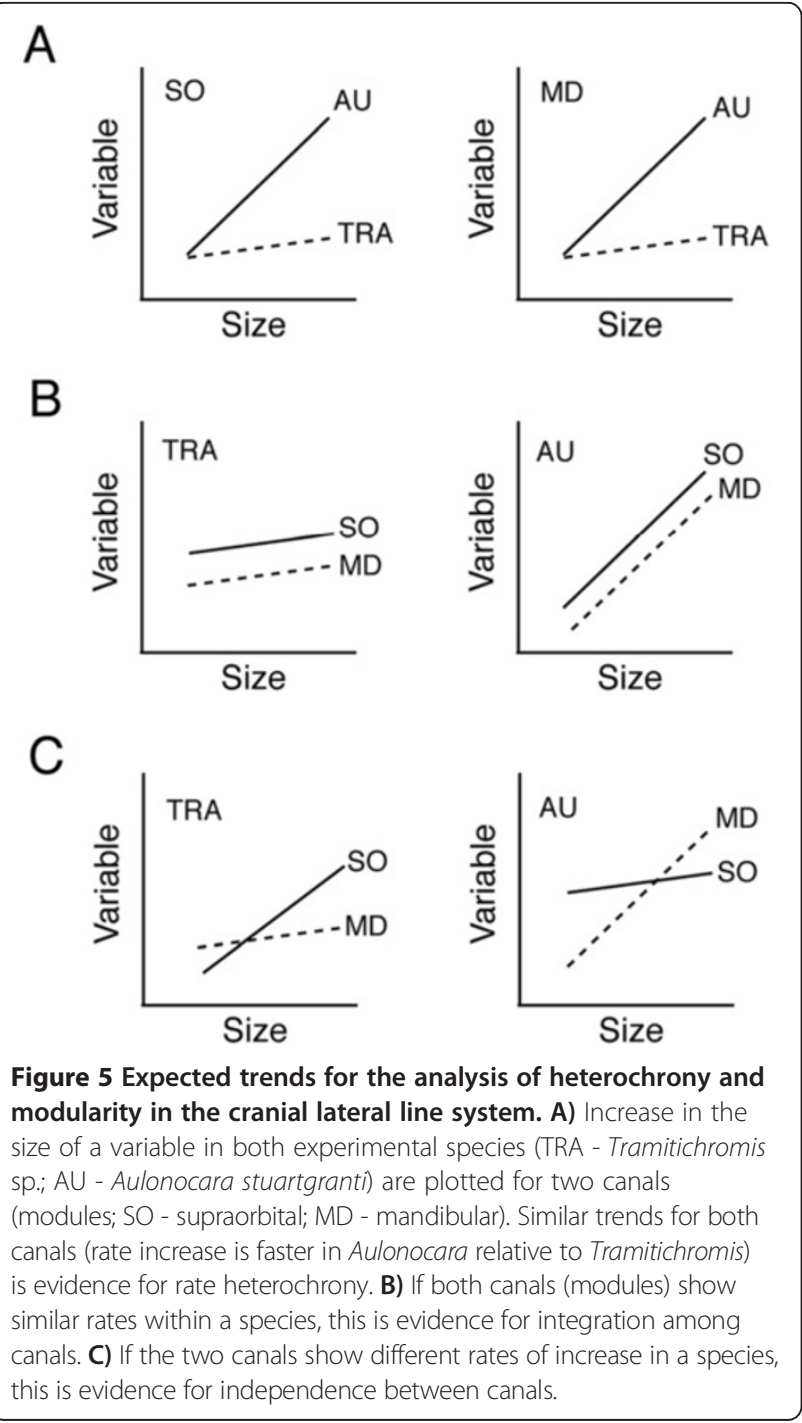

normally distributed (Goodness of Fit tests; JMP, v.10.0.2, SAS Institute, Inc, Cary, North Carolina, USA), so data transformation was not required. SL = standard length in $\mathrm{mm}$ (fish size) in all analyses including those in supplementary tables. Significance was defined a priori as $P<0.05$ for all analyses.

Analyses of developmental rates were carried out with reference to each of the three variables (canal diameter, neuromast length, neuromast width). For a particular variable, if the slopes of the regressions being compared between species (at the level of canal, canal portion, or canal segment) were not statistically different, the data were then tested for mean (elevation) differences using either a Student's $t$-test (two groups) or Tukey's honest significant difference (HSD) test (more than two groups). If slopes were different (significant ANCOVA interaction term), the data were subjected to the Johnson-Neyman procedure [51], which identifies the range of $x$-values (fish size) in which the variable of interest (on y axis) is not statistically different between groups [52], and thus the range in which the parameters are statistically different.

Heterochronic shifts in the onset of developmental events needed to be identified differently. The canal segments that compose a lateral line canal are known to develop asynchronously in other cichlids [29,47], and thus, it was expected that each canal segment in the SO and the MD canals would not necessarily be observed at all four developmental stages (I-IV) among individuals analyzed in this study (as in [47]). Thus, mean fish size at first canal enclosure (Stage III) and canal ossification (Stage IV) for each segment within a canal (SO1 to 5; MD1 to 5), and minimum canal diameter at first canal enclosure (Stage III) and canal ossification (Stage IV) for each segment within a canal, were used to approximate the onset of these processes.

The structural organization of the cranial lateral line canal system (as described above) also lends itself to a consideration of modularity (relative degree of integration and dissociation among modules [6,53-57]). ANCOVA's were carried out to determine if canal diameter and neuromast size (length, width) in different canals (SO, MD), different portions within a canal, and among segments that compose a canal, demonstrate the same (integration, Figure 5B) or different (dissociation, Figure 5C) developmental rates within each of the two study species.

\section{Results}

Hatching occurred prior to $7 \mathrm{dpf}$ in both Tramitichromis and Aulonocara. Yolk sac absorption started by $8 \mathrm{dpf}$ and was complete by 20 to $22 \mathrm{dpf}$ (at 10 to $11 \mathrm{~mm} \mathrm{SL}$ ), when young normally emerge from the mother's mouth. Neuromasts were evident at hatch, and presumptive 
canal neuromasts (those that will become enclosed in the lateral line canals) then became distinct in size from superficial neuromasts that remain on the skin (Figures 6 and 7). Canal enclosure started at 8 and $11 \mathrm{~mm} \mathrm{SL} \mathrm{(11}$ and $16 \mathrm{dpf}$ ) in the SO canal, and at 10 and $11 \mathrm{~mm} \mathrm{SL} \mathrm{(23}$ and $19 \mathrm{dpf}$ ) in the MD canal in Tramitichromis and Aulonocara, respectively (Figure 7).

Canal neuromast number and distribution (Figure 6), and the process of neuromast-centered canal morphogenesis ([29]; Figures 2, 7, 8) were the same in the two species (see also [47]). As expected from prior descriptions of the lateral line system of cichlids (Figure 1A-C; $[29,42,43,47])$, neuromast SO1 was found in the portion of the SO canal in the nasal bone, while neuromasts $\mathrm{SO} 2$ to 5 were found in the portion of the SO canal in the frontal bone (Figures 1D,E,G,H; 3, 6, 7). Neuromasts MD1 to 4 were found in the portion of the MD canal in the dentary bone, while neuromast MD5 was found in the portion of the MD canal in the anguloarticular bone (Figures 1C,F,I; 3, 7, 9).

The overall pattern and timing of the ossification of cranial bones, including those that contain the lateral line canals, were similar in the two species (Figure 9). Initial bone ossification was apparent in young larvae $(9 \mathrm{~mm} \mathrm{SL})$ in the upper and lower jaws (including the mandible, which will contain the MD canal) and pharyngeal jaws, the hyoid arch elements and opercular apparatus, and the parasphenoid (Figure 9A,D). Some ossification of the MD canal was visible, in addition to ossification of the dentary and anguloarticular. In older larvae of both species (11.5 mm SL, Figure 9B,E), the size at which young typically emerge from the mother's mouth, additional ossification was present throughout the cranium, including the frontal bone, and both the SO canal (in the frontal bone) and MD canal (in the mandible). In juveniles of both Tramitichromis and Aulonocara (Figure 9C,F), ossification was present throughout the cranium, including ossification of all five canal segments composing the $\mathrm{SO}$ and $\mathrm{MD}$ canals (Figure 9G-J).

\section{Heterochrony analysis}

Tramitichromis and Aulonocara grew at similar rates (approximately $0.2 \mathrm{~mm} \mathrm{SL} /$ day, Figure 3), but variation in the rate of increase of SO and MD canal diameter, neuromast length and neuromast width, were evident between species. MD canal diameter (at locations of neuromasts MD 1 to 5) increased at a rate of 2.2 to $3.8 \mu \mathrm{m} /$ day in Aulonocara, but increased at a rate of only 1.6 to $1.8 \mu \mathrm{m} /$ day in Tramitichromis. Canal neuromasts were diamond-shaped in both species (Figure 7L), but appeared to differ in relative length and width between canals and between species (unpublished data). Neuromast length (parallel to canal axis) increased in Aulonocara at a rate of 1.4 to $2.0 \mu \mathrm{m} /$ day, and increased at a comparable rate of 1.5 to $2.1 \mu \mathrm{m} /$ day in Tramitichromis. In contrast, neuromast width (perpendicular to canal axis) increased in Aulonocara at a higher rate
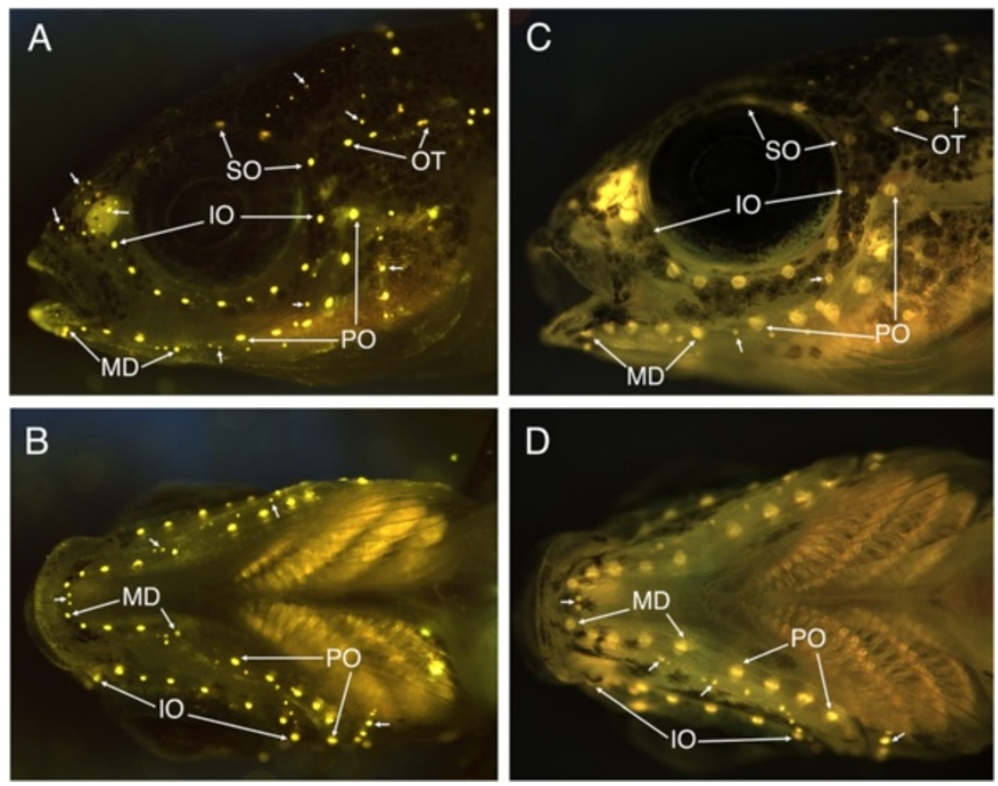

Figure 6 Fluorescent imaging of neuromasts in Tramitichromis sp. and Aulonocara stuartgranti using 4-di-2-ASP. A, B) Lateral and ventral views of Tramitichromis sp. (11 mm SL), with arrows pointing to first and last canal neuromasts in the supraorbital (SO), infraorbital (IO), preopercular (PO), mandibular (MD) and otic/post-otic (OT) series. Small arrows point to various groups of superficial neuromasts (see [58] for naming). C, D) Lateral and ventral views of Aulonocara stuartgranti (11.5 mm SL) labeled as in $\mathbf{A}$ and $\mathbf{B}$. In this individual (the same as visualized with SEM in Figure 7D), the fluorescent label illuminates the entire neuromast (hair cells and surrounding support cells) revealing their diamond shape (as in Figure $7 \mathrm{~L}$ ). 

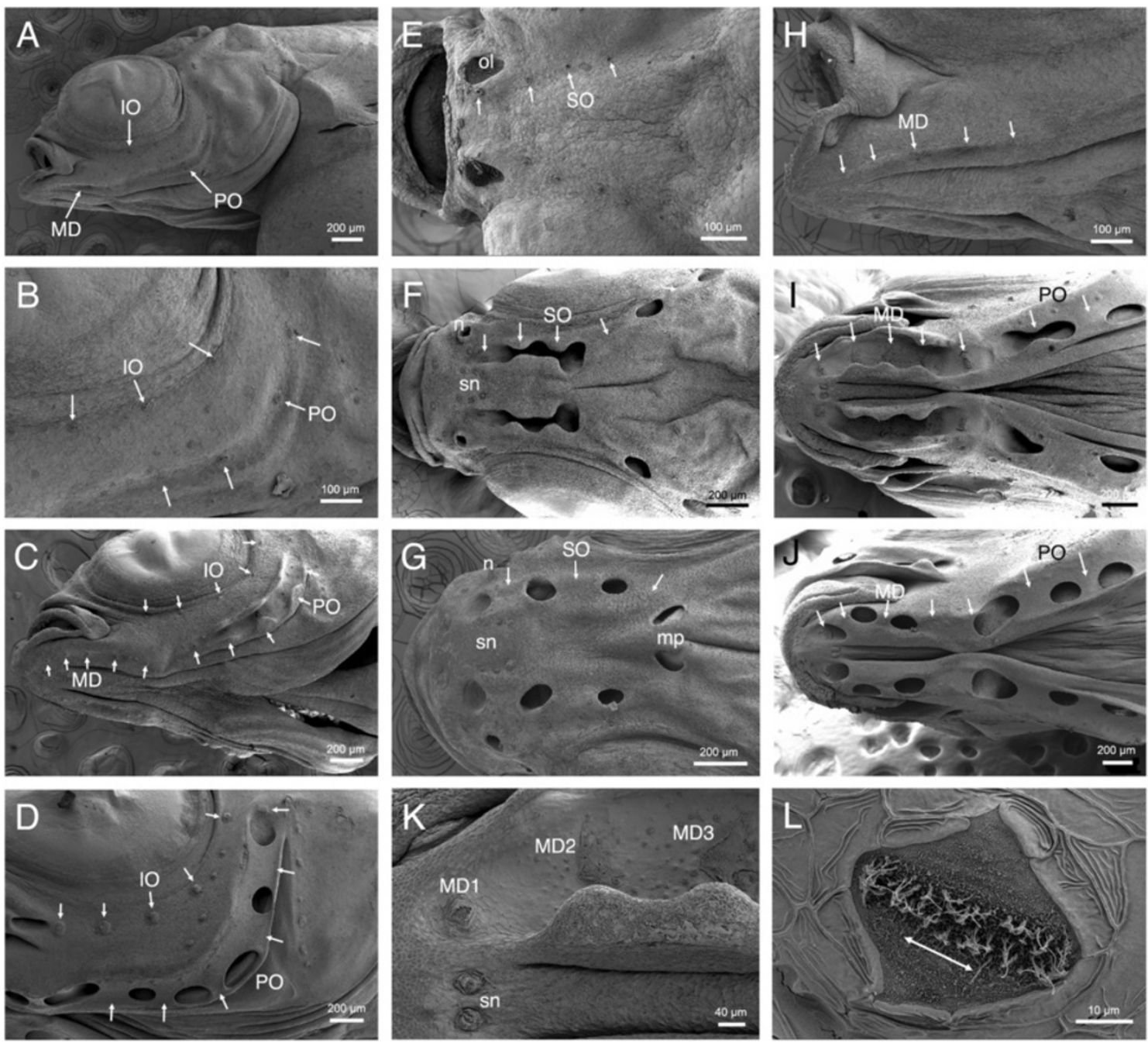

Figure 7 Neuromasts and canal morphogenesis in Aulonocara stuartgranti and Tramitichromis sp. visualized with SEM. All SEM images are of late stage larvae and juveniles of Aulonocara, with the exception of $\mathbf{C}$, which is of Tramitichromis. Arrows indicate presumptive CNs or position of CNs after canal enclosure; rostral to left in all images; see Figure 2 and 8 for definitions of St. 1 to St. 4. A) Infraorbital (IO), mandibular (MD) and preopercular (PO) presumptive CNs (canal neuromasts) in yolk sac larva (y, yolk; $7.5 \mathrm{~mm} \mathrm{SL).} \mathrm{B)} \mathrm{Close-up} \mathrm{of} \mathrm{A} \mathrm{showing} \mathrm{IO} \mathrm{CNs} \mathrm{at} \mathrm{St.} \mathrm{I,} \mathrm{PO} \mathrm{CNs} \mathrm{at} \mathrm{St.} \mathrm{Ila.}$ C) Tramitichromis sp. (7.5 mm SL): IO CNs at St. I, MD (MD1 to MD5) at St. I, and PO CNs at St. I or St. Ilb. D) IO CNs at St. I and PO CNs at St. III/IV (11.5 mm; same individual as in Figure 6C,D). Other neuromasts are small SNs (superficial neuromasts) that remain on skin. E) Four supraorbital (SO) CNs; SO1 is medial to olfactory organ (ol) (6.0 mm SL). F) SO canal with SO1 at St. I, medial to naris (n), SO2 and SO3 at St. IIb; SO 4 and SO5 at St. III/IV; SNs visible between SO canals (sn; $9.5 \mathrm{~mm} \mathrm{SL)}$. G) SO canal at St. III/IV, arrows indicate SO1 to SO3; two pores caudal to position of right and left SO3 CNs will fuse to form medial pore (mp) (10 mm SL). H) Mandibular CNs (MD1 to MD5) at St. Ila (7 mm SL). I) MD canal with MD1 at St. Ila, MD2 to 4 at St. IIb, and MD5 at St. Ila. First two PO CNs are at St. Ilb and St. III/V (11 mm SL). J) MD and PO canals enclosed (St. III/IV), arrows show MD1 to MD5 and first two PO CNs (12 mm SL). K) Close-up of left MD canal in I, showing MD1 at St. lla, and MD2 and MD3 at St. llb; small SNs (sn) are round in contrast to diamond-shaped canal neuromasts (11 mm SL). L) Close-up of diamond-shaped CN, MD1, showing location of sensory hair cells in sensory strip elongated parallel to physiological orientation of hair cells and canal axis (double-headed arrow; 10 mm SL).

of 3.3 to $4.2 \mu \mathrm{m} /$ day, but at a rate of only 1.6 to $1.8 \mu \mathrm{m} /$ day in Tramitichromis.

Analyses of the rates of increase in canal diameter and in neuromast length and width in the SO and MD canals (data combined) revealed a higher rate of increase in both canal diameter and neuromast width in Aulonocara relative to Tramitichromis (Figure 10, Tables 1 and 2). Canal diameter increased approximately 2.0 times faster, and neuromast width increased approximately 1.8 times faster in Aulonocara relative to Tramitichromis (Table 2, Figure 10A,C). As a result, Aulonocara already had wider canals than Tramitichromis in young larvae $\geq 8.6 \mathrm{~mm} \mathrm{SL}$, and wider neuromasts in larvae $\geq 9.1 \mathrm{~mm}$ SL (Table 3), which is well before the normal time of release from the mother's mouth. The rate of increase in neuromast length was not statistically different in the two species (Table 1, Figure 10B). 


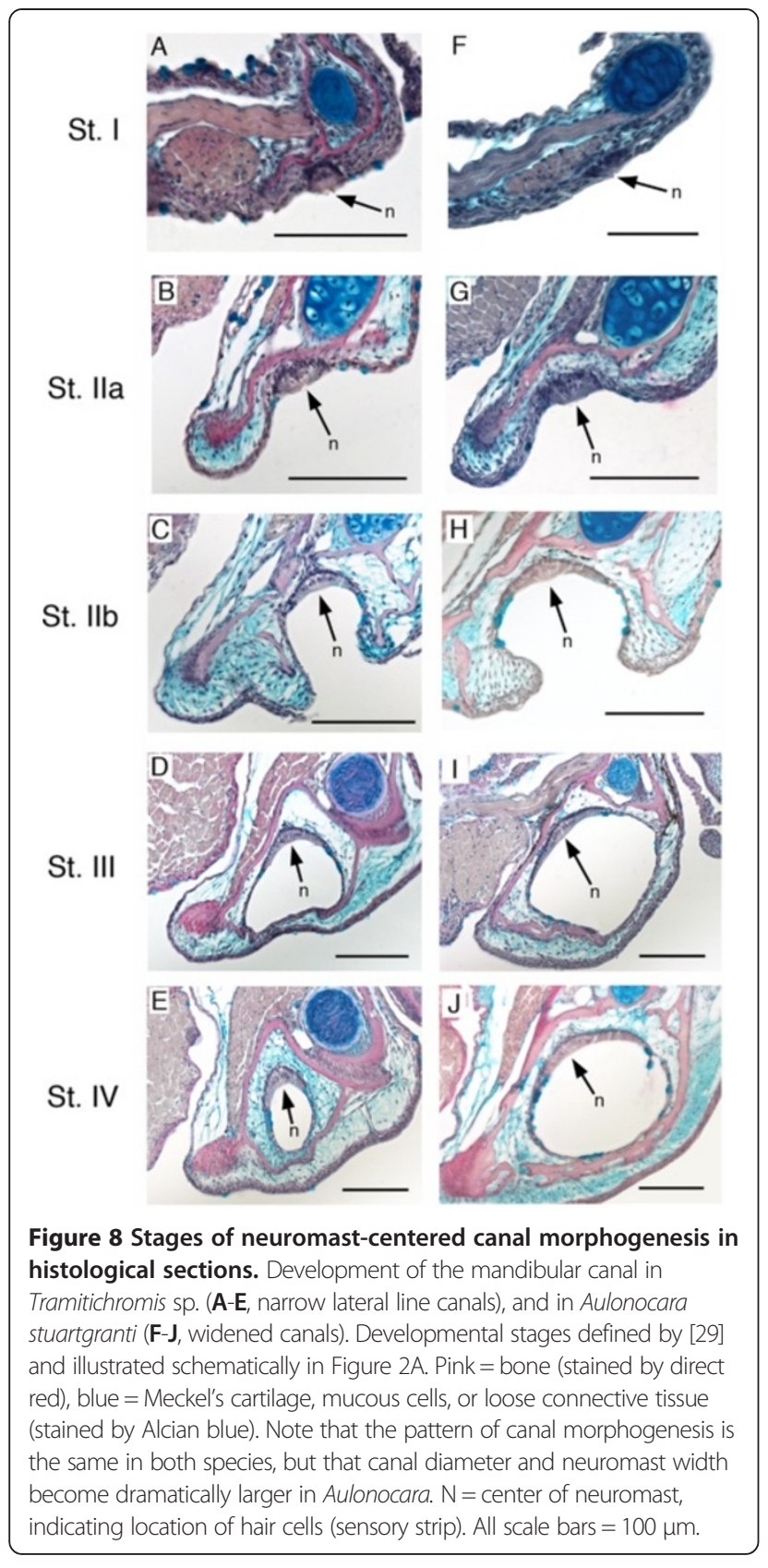

When the SO and MD canals were considered separately, the rates of increase in canal diameter and neuromast width in each canal were also higher in Aulonocara than in Tramitichromis (Tables 1, 2, Figure 10D,F,G,I). SO and MD canal diameter both increased approximately 2.0 times faster in Aulonocara (Table 2, Figure 10D,G) such that Aulonocara already had wider SO canals than Tramitichromis in small larvae $\geq 8.0 \mathrm{~mm} \mathrm{SL}$ and wider MD canals in larvae $\geq 9.9 \mathrm{~mm}$ SL (Table 3). SO and MD neuromast width increased 1.8 to 1.9 times faster in Aulonocara, respectively (Table 2, Figure 10F,I), such that Aulonocara already had wider SO and MD neuromasts than in Tramitichromis in young larvae $\geq 9.4 \mathrm{~mm} \mathrm{SL}$ (Table 3). The rate of increase of SO neuromast length was not statistically different between species (Tables 1, 2, Figure 10E), but SO neuromasts were consistently longer in Aulonocara than in Tramitichromis (Additional file 1: Table S1). In contrast, MD neuromast length increased 1.3 times faster in Tramitichromis than in Aulonocara (Table 2, Figure 10H), but, MD neuromasts in Aulonocara were already longer than those in Tramitichromis in small larvae, allowing MD neuromast length Tramitichromis to catch up to Aulonocara by the time larvae were $\geq 12.6 \mathrm{~mm}$ SL (Table 3 ).

When the two canal portions in the SO and in the MD canals were considered separately, the rates of increase in canal diameter and in neuromast width were found to be faster in Aulonocara than in Tramitichromis (Additional file 1: Table S2). Canal diameter increased 1.8 to 2.3 times faster (Additional file 1: Table S3), and neuromast width increased 1.8 to 2.0 times faster, in each of the two portions of the SO and the MD canals (Additional file 1: Table S3). As a result, the two canal portions in the SO and in the MD canals were wider in Aulonocara than in Tramitichromis in young larvae of $>7.8$ to $10.5 \mathrm{~mm} \mathrm{SL}$ and neuromasts were already wider in Aulonocara in larvae of $>9.4$ to $10.0 \mathrm{~mm}$ SL (Table 3). The rates of increase in neuromast length in the two portions of the $\mathrm{SO}$ and $\mathrm{MD}$ canals revealed a rate difference in the neuromasts in the dentary portion of the MD canal (MD1 to MD4; Additional file 1: Table S2). In contrast, the rate of increase in neuromast length was slower $(0.74 \mathrm{x})$ in Aulonocara than in Tramitichromis. The rate of increase in neuromast length in both SO canal portions and in the anguloarticular portion of the MD canal were the same in the two species (Additional file 1: Table S3).

When the five canal segments in the SO (1 to 5) and in the MD (1 to 5) canals were considered separately, rates of increase in canal diameter and neuromast size (length, width) showed inconsistent patterns (Additional file 1: Tables S4-S6). For instance, most but not all MD segments demonstrated a higher rate of increase in canal diameter (Additional file 1: Table S4, S7) and neuromast width in Aulonocara (Additional file 1: Table S6, S7). Overall, variability in rate of increase and the size at which the two species demonstrated statistical differences in morphology was more extensive in analyses of individual canal segments (Table 3).

The analysis of developmental rates for canal diameter, neuromast length and neuromast width within each species at the level of canal, canal portion and canal segment revealed few rate differences that would indicate the presence of local heterochronies within species and thus modularity. Rates of increase in SO and MD canal diameter and neuromast size (length, width) were not statistically different between canals in either species (Tables 2 and 4, Figure 11). The two portions of the SO 

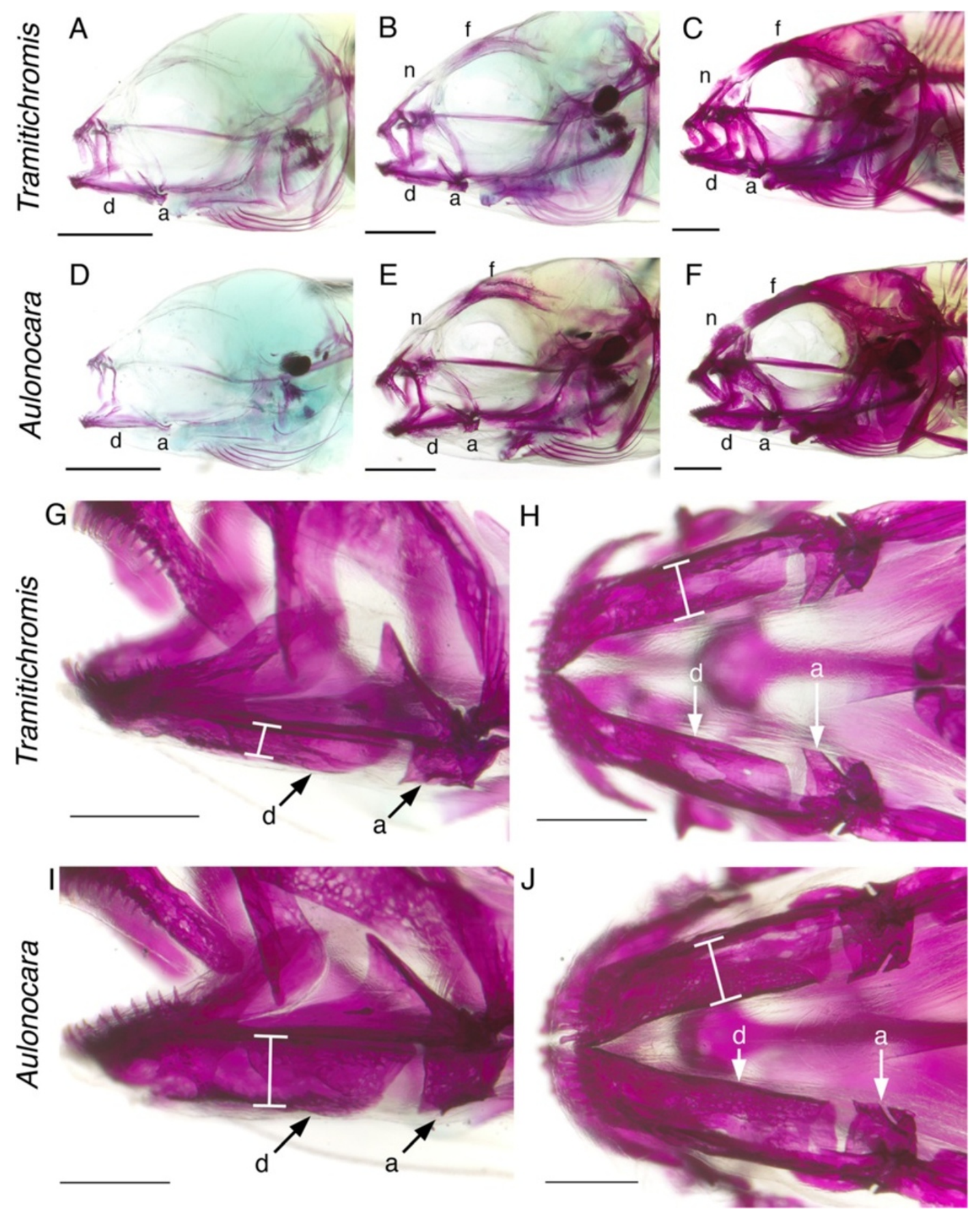

Figure 9 Bone ossification in cleared and stained larval and juvenile Tramitichromis sp. and Aulonocara stuartgranti. Overall

developmental sequence is similar in Tramitichromis sp. (A-C) and Aulonocara stuartgranti (D-F; lateral views, rostral to the left). Early larval development (A, D; 9 mm SL) showing ossification in jaws and opercular region. The dentary (d) and anguloarticular (a) bones are ossified in both species, but the SO canal is not yet ossified. Older larvae (B, E; $11.5 \mathrm{~mm} \mathrm{SL)} \mathrm{show} \mathrm{ossification} \mathrm{spreading} \mathrm{to} \mathrm{the} \mathrm{otic} \mathrm{and} \mathrm{orbital} \mathrm{regions.} \mathrm{The}$ frontal ( $f$ ) and nasal (n) bones are weakly ossified, and the dentary and anguloarticular bones are strongly ossified. Juveniles (C, Tramitichromis, $14 \mathrm{~mm} \mathrm{SL;} \mathbf{F}$, Aulonocara, $16 \mathrm{~mm} \mathrm{SL}$ ) show ossification throughout the cranium. Close ups (G-J) of specimens in C and F illustrate the MD canal in lateral $(\mathbf{G}, \mathbf{I})$ and ventral $(\mathbf{H}, \mathbf{J})$ views (rostral to the left). Note that the canals are wider in Aulonocara than in Tramitichromis (white brackets). Scale bars: A-F $=1.0 \mathrm{~mm}, \mathrm{G}-J=0.5 \mathrm{~mm}$. MD, mandibular canal; SO, supraorbital canal. 


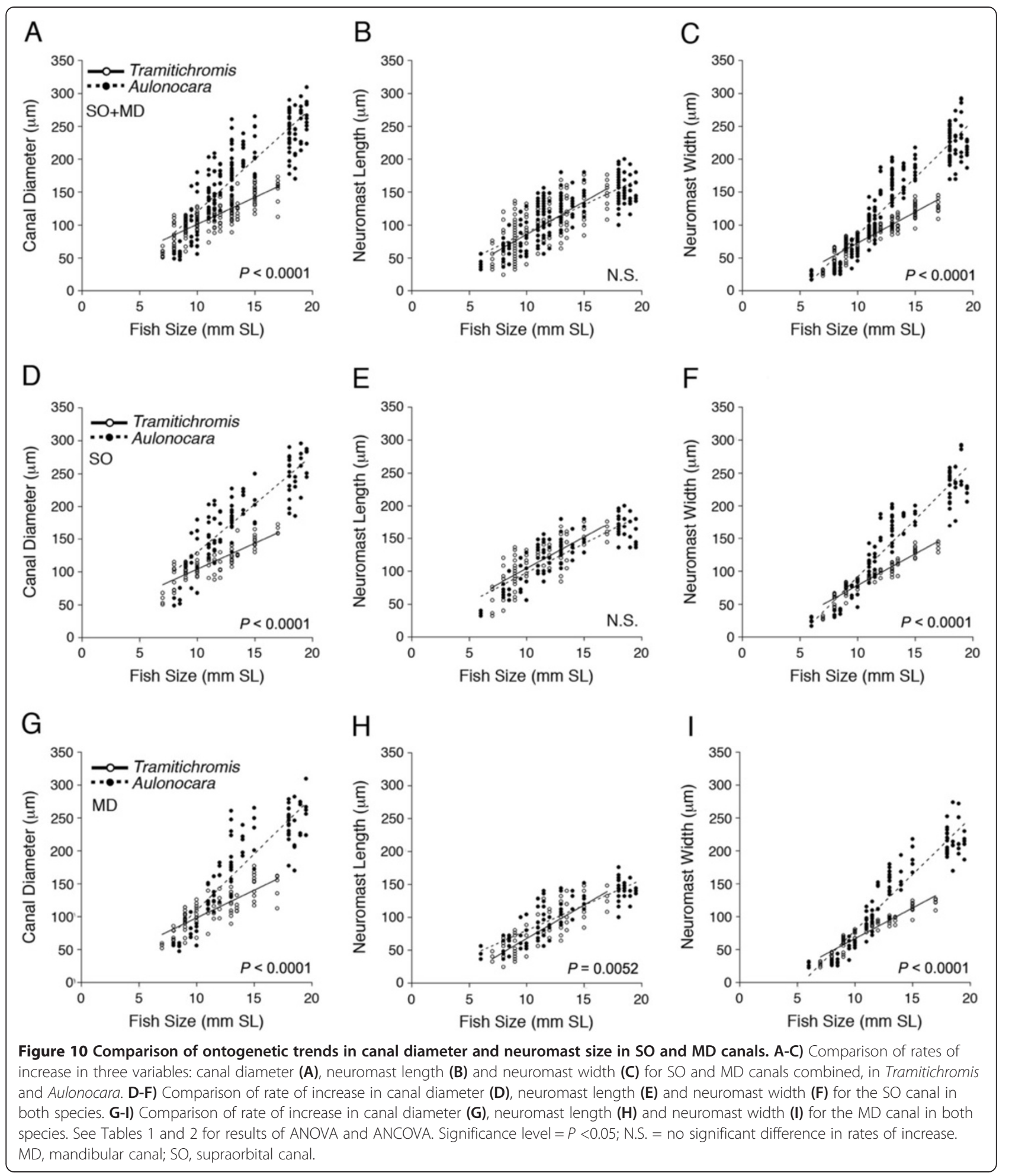

canal and the MD canal demonstrated similar rates of increase in canal diameter and neuromast size in each species (Additional file 1: Tables S3 and S8). In contrast, the analysis of developmental rates among $\mathrm{SO}$ and among $\mathrm{MD}$ canal segments revealed some variability, but consistent patterns could not be detected in either species (Additional file 1: Tables S7 and S9).

Finally, a consideration of the correlation between neuromast size and canal diameter also showed some interesting trends (Figure 12, Table 5). In Tramitichromis, SO 
Table 1 ANCOVA for canal diameter and neuromast size (length, width) in the supraorbital and mandibular canals in two species

\begin{tabular}{|c|c|c|c|c|c|}
\hline & $N$ & $R^{2}$ & $F$ & d.f. & $P$ \\
\hline Canal diameter (combined) & 358 & 0.83 & & & \\
\hline Species & & & 175.4131 & 1,354 & $<.0001$ \\
\hline SL & & & 732.5361 & 1,354 & $<.0001$ \\
\hline Species $\times$ SL & & & 77.8231 & 1,354 & $<.0001$ \\
\hline Canal diameter (SO) & 184 & 0.85 & & & \\
\hline Species & & & 128.5339 & 1,180 & $<.0001$ \\
\hline SL & & & 391.6134 & 1,180 & $<.0001$ \\
\hline Species $\times$ SL & & & 36.1964 & 1,180 & $<.0001$ \\
\hline Canal diameter (MD) & 174 & 0.83 & & & \\
\hline Species & & & 62.1329 & 1,170 & $<.0001$ \\
\hline SL & & & 369.4595 & 1,170 & $<.0001$ \\
\hline \multirow[t]{2}{*}{ Species x SL } & & & 43.2358 & 1,170 & $<.0001$ \\
\hline & $N$ & $R^{2}$ & $F$ & d.f. & $P$ \\
\hline Neuromast length (combined) & 389 & 0.61 & & & \\
\hline Species & & & 0.0775 & 1,385 & 0.7809 \\
\hline SL & & & 494.8616 & 1,385 & $<.0001$ \\
\hline Species x SL & & & 3.7681 & 1,385 & 0.0530 \\
\hline Neuromast length (SO) & 194 & 0.69 & & & \\
\hline Species & & & 6.0854 & 1,190 & 0.0145 \\
\hline SL & & & 346.0935 & 1,190 & $<.0001$ \\
\hline Species x SL & & & 0.4571 & 1,190 & 0.4998 \\
\hline Neuromast length (MD) & 195 & 0.73 & & & \\
\hline Species & & & 5.1958 & 1,191 & 0.0237 \\
\hline SL & & & 405.6425 & 1,191 & $<.0001$ \\
\hline \multirow[t]{2}{*}{ Species $\times$ SL } & & & 7.987 & 1,191 & 0.0052 \\
\hline & $N$ & $R^{2}$ & $F$ & d.f. & $P$ \\
\hline Neuromast width (combined) & 389 & 0.89 & & & \\
\hline Species & & & 179.7582 & 1,385 & $<.0001$ \\
\hline SL & & & 1548.252 & 1,385 & $<.0001$ \\
\hline Species x SL & & & 135.6519 & 1,385 & $<.0001$ \\
\hline Neuromast width (SO) & 194 & 0.9 & & & \\
\hline Species & & & 96.0182 & 1,190 & $<.0001$ \\
\hline SL & & & 809.9263 & 1,190 & $<.0001$ \\
\hline Species x SL & & & 71.6976 & 1,190 & $<.0001$ \\
\hline Neuromast width (MD) & 195 & 0.91 & & & \\
\hline Species & & & 104.6486 & 1, 191 & $<.0001$ \\
\hline SL & & & 916.1915 & 1,191 & $<.0001$ \\
\hline Species x SL & & & 79.312 & 1,191 & $<.0001$ \\
\hline
\end{tabular}

Analysis was carried out for supraorbital (SO) and mandibular (MD) canals together (combined) or individually in Tramitichromis and Aulonocara. $\mathrm{SL}=$ Standard length (fish size) in $\mathrm{mm}$. All data were found to be normal. Significance $=P<0.05$. The Johnson-Neyman procedure was used to determine the region of non-significance for fish size for ANCOVAs with significant interaction terms (indicating heterogeneity of slopes, see text and Table 3 for additional details). See Figure 10 and Table 2 for ANOVA results and individual regressions. neuromast length (Figure 12A) and width (Figure 12C) both appeared to increase isometrically (slope approximately $=1$ ) with canal diameter. In the MD canal, neuromast length (Figure 12E) appeared to increase isometrically with canal diameter, but neuromast width (Figure 12G) appeared to increase at a slower rate (Table 5). In Aulonocara, neuromast width (Figure 12D,H) appeared to increase isometrically with canal diameter in both the $\mathrm{SO}$ and MD canals (Table 5). In contrast, neuromast length increased slowly with canal diameter in either the SO or MD canals (Figure 12B,F, Table 5).

\section{Timing of onset of canal enclosure and ossification}

Fish size at first enclosure (Stage III, Figure 8D,I) and at ossification (Stage IV, Figure 8E,J) for each canal segment within a canal were used to approximate differences in time of onset of these critical stages of canal morphogenesis (Table 6). SO canal segments tended to enclose in a caudal to rostral direction in both species (Figure 13A,B), but the onset of $\mathrm{SO}$ segment enclosure tended to occur in larger individuals of Aulonocara than of Tramitichromis. MD canal segments appeared to enclose bi-directionally, starting with MD3 (Figure 13C,D) in both species, but as in the $\mathrm{SO}$ canal, the onset of enclosure occurred in larger individuals of Aulonocara than of Tramitichromis (Table 6). The MD1 segment was the last of the MD segments to enclose in Aulonocara (at approximately $18 \mathrm{~mm}$ SL; Figure 7I,K), and had not enclosed in Tramitichromis in the largest of individuals examined. Ossification of the SO and MD canal segments was also delayed, with onset in larger individuals of Aulonocara than Tramitichromis. The order of canal ossification tended to occur in a caudal-to-rostral direction in the SO in both species. The order of ossification among segments in the MD canal could not be discerned in Aulonocara, but the order of canal segment ossification was bi-directional in Tramitichromis starting with MD3 and progressing both rostrally and caudally (Figure 13).

The delay of onset of SO and MD canal segment enclosure (Figures 10 and 13) resulted in canal segment enclosure and ossification at larger diameters in Aulonocara than in Tramitichromis (Table 6, Figures 8, 13). SO canal segment enclosure started at diameters of $>100 \mu \mathrm{m}$ in Aulonocara, but at smaller diameters $(<100 \mu \mathrm{m})$ in Tramitichromis. Subsequent ossification (which occurred after some expansion of canal diameter) started at diameters of up to $>200 \mu \mathrm{m}$ in Aulonocara, but at smaller diameters $(<150 \mu \mathrm{m})$ in Tramitichromis. Similarly, MD canal segment enclosure started at diameters of up to $>200 \mu \mathrm{m}$ in Aulonocara, but at smaller diameters $(<150 \mu \mathrm{m})$ in Tramitichromis. Subsequent ossification of MD canal segments started at canal diameters of $>200 \mu \mathrm{m}$ in Aulonocara, but at smaller diameters $(<150 \mu \mathrm{m})$ in Tramitichromis. 
Table 2 Results of ANOVA for canal diameter and neuromast size (length, width) in the SO and MD canals in Tramitichromis and Aulonocara

\begin{tabular}{|c|c|c|c|c|}
\hline & $N$ & Regression & $R^{2}$ & $P$ \\
\hline \multicolumn{5}{|c|}{ Canal diameter (combined) } \\
\hline Tramitichromis & 175 & $C D=8.11 \times S L+20.24$ & 0.66 & $<.0001$ \\
\hline Aulonocara & 183 & $C D=15.96 \times S L-39.27$ & 0.76 & $<.0001$ \\
\hline \multicolumn{5}{|c|}{ Canal diameter (SO) } \\
\hline Tramitichromis & 90 & $C D=7.9 \times S L+25.16$ & 0.71 & $<.0001$ \\
\hline Aulonocara & 94 & $C D=14.81 \times S L-17.83$ & 0.75 & $<.0001$ \\
\hline \multicolumn{5}{|c|}{ Canal diameter (MD) } \\
\hline Tramitichromis & 85 & $\mathrm{CD}=8.41 \times S L+14.16$ & 0.64 & $<.0001$ \\
\hline \multirow[t]{2}{*}{ Aulonocara } & 89 & $C D=17.16 \times S L-61.74$ & 0.78 & $<.0001$ \\
\hline & $N$ & Regression & $R^{2}$ & $P$ \\
\hline \multicolumn{5}{|c|}{ Neuromast length (combined) } \\
\hline Tramitichromis & 180 & $\mathrm{NML}=9.90 \times \mathrm{SL}-12.99$ & 0.51 & $<.0001$ \\
\hline Aulonocara & 209 & $\mathrm{NML}=8.31 \times S L+5.73$ & 0.65 & $<.0001$ \\
\hline \multicolumn{5}{|c|}{ Neuromast length (SO) } \\
\hline Tramitichromis & 90 & $\mathrm{NML}=9.57 \times \mathrm{SL}+8.68$ & 0.62 & $<.0001$ \\
\hline Aulonocara & 104 & $\mathrm{NML}=8.90 \times \mathrm{SL}+8.77$ & 0.71 & $<.0001$ \\
\hline \multicolumn{5}{|c|}{ Neuromast length (MD) } \\
\hline Tramitichromis & 90 & $\mathrm{NML}=10.23 \times S L-34.67$ & 0.7 & $<.0001$ \\
\hline \multirow[t]{2}{*}{ Aulonocara } & 105 & $\mathrm{NML}=7.71 \times S L+2.91$ & 0.7 & $<.0001$ \\
\hline & $N$ & Regression & $R^{2}$ & $P$ \\
\hline \multicolumn{5}{|c|}{ Neuromast width (combined) } \\
\hline Tramitichromis & 180 & NMW $=9.44 \times S L-21.67$ & 0.84 & $<.0001$ \\
\hline Aulonocara & 209 & $N M W=17.38 \times S L-88.66$ & 0.87 & $<.0001$ \\
\hline \multicolumn{5}{|c|}{ Neuromast width (SO) } \\
\hline Tramitichromis & 90 & NMW $=9.56 \times S L-16.92$ & 0.89 & $<.0001$ \\
\hline Aulonocara & 104 & $N M W=17.66 \times S L-85.10$ & 0.87 & $<.0001$ \\
\hline \multicolumn{5}{|c|}{ Neuromast width (MD) } \\
\hline Tramitichromis & 90 & $N M W=9.31 \times S L-26.42$ & 0.88 & $<.0001$ \\
\hline Aulonocara & 105 & $N M W=17.08 \times S L-92.06$ & 0.88 & $<.0001$ \\
\hline
\end{tabular}

Analysis was carried out for supraorbital (SO) and mandibular (MD) canals together (combined) or individually in Tramitichromis and Aulonocara. SL = standard length (fish size) in mm. Significance level $=P<0.05$. All data were normally distributed. See Figures 10 and 12 and Tables 1 and 5 for results of ANCOVAs. CD, canal diameter; NML, neuromast length; NMW, neuromast width.

\section{Discussion}

\section{Heterochrony and the evolution of widened lateral line} canals

The cranial lateral line canal systems of Aulonocara and Tramitichromis contain the same number of canal neuromasts and are characterized by the same pattern of neuromast-centered canal morphogenesis. Nevertheless, the quantitative analysis of canal and neuromast development reported here has demonstrated that the evolution of the widened canal phenotype is the result of heterochrony, and of dissociated heterochrony, in particular. Dissociated heterochrony, defined as a mixture of positive and negative heterochronic shifts (peramorphosis and paedomorphosis of [12]) was illustrated by a higher rate of increase in canal diameter and neuromast width, but a delay in the onset and duration of canal enclosure and ossification in Aulonocara relative to Tramitichromis. The presence of large canal pores in the widened canals in Aulonocara compared to those in Tramitichromis is predicted to be the result of either a truncation (earlier offset) or a deceleration in the process of canal roof ossification.

Neuromast width is clearly constrained by canal diameter, but neuromast length is only constrained by the close proximity of adjacent neuromasts, which influences the process of neuromast-centered canal morphogenesis by determining the location, spacing, and size of pores (Figures 2, 7 and 8). The ability of neuromast shape to vary in both developmental and evolutionary time is 
Table 3 Results of Johnson-Neyman procedure for identifying a region of non-significance in fish size (mm SL) for canal diameter and neuromast shape

\begin{tabular}{|c|c|c|c|}
\hline & & Variables & \\
\hline & Canal diameter & Neuromast length & Neuromast width \\
\hline \multicolumn{4}{|l|}{ Canals } \\
\hline SO Canal & $>8.0 \mathrm{~mm} \mathrm{SL}$ & N/A & $>9.4 \mathrm{~mm} \mathrm{SL}$ \\
\hline MD Canal & $>9.9$ & $<12.6^{*}$ & $>9.4$ \\
\hline \multicolumn{4}{|l|}{ Canal Portions } \\
\hline Nasal (SO) & $>10.3$ & N/A & $>10.0$ \\
\hline Frontal (SO) & $>7.8$ & N/A & $>9.4$ \\
\hline Dentary (MD) & $>10.1$ & $<12.5^{*}$ & $>9.5$ \\
\hline Anguloarticular (MD) & $>10.5$ & N/A & $>9.8$ \\
\hline \multicolumn{4}{|l|}{ Canal Segments } \\
\hline SO1 & $>10.3$ & N/A & $>10.0$ \\
\hline $\mathrm{SO} 2$ & N/A & N/A & $>10.0$ \\
\hline $\mathrm{SO} 3$ & $>8.2$ & N/A & $>10.1$ \\
\hline $\mathrm{SO} 4$ & $>12.2$ & N/A & $>11.8$ \\
\hline SO5 & $>9.3$ & $>12.7^{* *}$ & $>9.8$ \\
\hline MD1 & N/A & N/A & $>10.3$ \\
\hline MD2 & $>10.9$ & N/A & $>10.0$ \\
\hline MD3 & $>11.3$ & $<11.9^{*}$ & $>10.2$ \\
\hline MD4 & $>11.5$ & N/A & $>10.4$ \\
\hline MD5 & $>10.5$ & N/A & $>9.8$ \\
\hline
\end{tabular}

This statistical procedure was carried out for data analyzed at each level in the lateral line system (canal, canal portion, canal segment; see text for additional information) in the supraorbital (SO) and mandibular (MD) canals for which ANCOVAs demonstrated significantly different slopes between species. Numerical values represent the fish size ( $\mathrm{mm} \mathrm{SL}$ ) above which Aulonocara has wider canal diameters, longer neuromast lengths, and/or wider neuromast widths, except as noted. *fish size (mm SL) below which the variable has a higher value in Aulonocara than in Tramitichromis. ${ }^{* *}$ fish size (mm SL) above which the variable has a higher value in Tramitichromis than in Aulonocara. N/A indicates that the slopes comparing trends for Aulonocara and Tramitichromis were not statistically different, so the Johnson-Neyman procedure was not used.

predicted to have important implications for mechanosensory function (detection of water flows, [59]).

The mechanisms underlying heterochronic change are not revealed by the analysis of developmental patterns. However, it is predicted that the evolution of lateral line canal phenotype is the result of system-wide changes in genetic regulation of neuromast growth (for example, support cell and hair cell differentiation) and/or canal morphogenesis (for example, osteogenesis and remodelling of dermal bone). The correlation between the rate of increase in canal diameter and neuromast width (demonstrated by isometric trend in Aulonocara) suggests that there is either a developmental interaction between presumptive canal neuromasts and canal bone (for example, neuromast induction of canal morphogenesis, [60-63]), or a common developmental mechanism guiding the development of both of these tissue types.

\section{A consideration of modularity in the cranial lateral line system}

Modules are defined as parts of developmental or genetic networks, or phenotypes, that compose a hierarchy within an organism $[64,65]$ that can be identified in functional, anatomical, developmental or genetic contexts [7]. Modularity is defined by the interplay between independence among modules and integration among elements within a module [6,53-57,66,67]. The detection of modules allows a more robust picture of morphological evolution [66]. The relationship between modularity and evolution can be revealed by the examination of development at both global and local levels, which may reveal vastly different evolutionary patterns [13]. It has been suggested that the precise relationship between modularity and heterochrony is unknown [67], but, if modularity is required for heterochrony to occur at local scales $[13,26]$, then the detection of local heterochronies within species $[13,54,68]$ may be used to identify potential sites of independence or dissociation, [6] among modules. Furthermore, the ability to respond to demands for evolutionary change $[6,69]$, including those that occur via heterochrony (for example, those shown in this study), will be dependent on the degree of independence among modules. 
Table 4 ANCOVA for canal diameter and neuromast size in the SO and MD canals combined in Tramitichromis and Aulonocara

\begin{tabular}{|c|c|c|c|c|c|}
\hline & $\mathrm{N}$ & $\mathrm{R}^{2}$ & $\mathrm{~F}$ & d.f. & $P$-value \\
\hline Canal diameter (Tramitichromis) & 175 & 0.67 & & & \\
\hline$S L$ & & & 348.0619 & 1,171 & $<.0001$ \\
\hline Canal & & & 5.0408 & 1,171 & 0.026 \\
\hline $\mathrm{SL} \times$ Canal & & & 0.3324 & 1,171 & 0.5650 \\
\hline Canal diameter (Aulonocara) & 183 & 0.77 & & & \\
\hline$S L$ & & & 582.8945 & 1,179 & $<.0001$ \\
\hline Canal & & & 5.708 & 1,179 & 0.0179 \\
\hline \multirow[t]{2}{*}{ SL x Canal } & & & 3.1312 & 1,179 & 0.0785 \\
\hline & $\mathrm{N}$ & $\mathrm{R}^{2}$ & $\mathrm{~F}$ & d.f. & $P$-value \\
\hline Neuromast length (Tramitichromis) & 180 & 0.74 & & & \\
\hline$S L$ & & & 338.8333 & 1,176 & $<.0001$ \\
\hline Canal & & & 149.0871 & 1,176 & $<.0001$ \\
\hline SL x Canal & & & 0.3759 & 1,176 & 0.5406 \\
\hline Neuromast length (Aulonocara) & 209 & 0.73 & & & \\
\hline$S L$ & & & 487.6754 & 1,205 & $<.0001$ \\
\hline Canal & & & 54.3751 & 1,205 & $<.0001$ \\
\hline \multirow[t]{2}{*}{ SL $\times$ Canal } & & & 2.4841 & 1,205 & 0.1165 \\
\hline & $\mathrm{N}$ & $\mathrm{R}^{2}$ & $\mathrm{~F}$ & d.f. & $P$-value \\
\hline Neuromast width (Tramitichromis) & 180 & 0.89 & & & \\
\hline SL & & & 1362.844 & 1,176 & $<.0001$ \\
\hline Canal & & & 76.2438 & 1,176 & $<.0001$ \\
\hline SL x Canal & & & 0.2324 & 1,176 & 0.6304 \\
\hline Neuromast width (Aulonocara) & 209 & 0.88 & & & \\
\hline$S L$ & & & 1441.915 & 1,205 & $<.0001$ \\
\hline Canal & & & 16.9214 & 1,205 & $<.0001$ \\
\hline SL $\times$ Canal & & & 0.4012 & 1,205 & 0.5272 \\
\hline
\end{tabular}

Analysis was carried out for supraorbital (SO) and mandibular (MD) canals combined in Tramitichromis and in Aulonocara. SL = Standard length (fish size) in mm. All data were normally distributed. Significance $=P<0.05$. The interaction terms in these ANCOVAs were significant, so the Johnson-Neyman technique was not used. See Figure 12 and Table 2 for ANOVA results and individual regressions.

The nature of the structural hierarchy that defines the cranial lateral line canal system strongly suggests a modular organization, which is defined as follows: 1) individual canal segments, 2) the series of canal segments that compose a lateral line canal (for example, $\mathrm{SO} 1$ to SO5, MD1 to SO5), 3) the portions of a canal in different dermal bones composed of one or more canal segments (for example, the portions of the SO canal in the nasal and frontal bones, and the portions of the MD canal in the dentary and anguloarticular bones), 4) each lateral line canal (for example, $\mathrm{MD}, \mathrm{SO}, \mathrm{IO}$ and $\mathrm{PO}$ canals), 5) the entire cranial lateral line canal system (all canals), and 6) the entire lateral line canal system (cranial and trunk canals). The superficial neuromasts on the head and trunk appear to comprise at least one additional component (or module) of the lateral line system, which demonstrates developmental trajectories and evolutionary trends different from those of the canal neuromasts $[58,70]$. The hypothesis that the cranial lateral line canal system is modular is also supported by the stereotyped location of canal neuromasts within individual canal segments (Figure 4), which is the result of neuromast-centered canal morphogenesis (Figures 2, 7 and 8), and the association of different lateral line canals with different dermal bones (Figure 1; $[60,71]$ ) that have distinct structural attributes, functional roles, and are subject to different constraints within the skull $[27,72,73]$.

The location of the lateral line canals within dermatocranial bones suggests that the structural (and thus functional) evolution of the lateral line canal system should be constrained by the developmental origins [74,75] and structural and/or functional demands of those dermal bones, and vice versa. However, if the morphology of the lateral line canals (and canal neuromasts) is to respond 
A

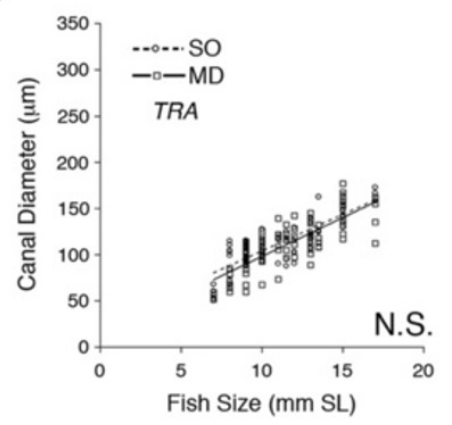

D

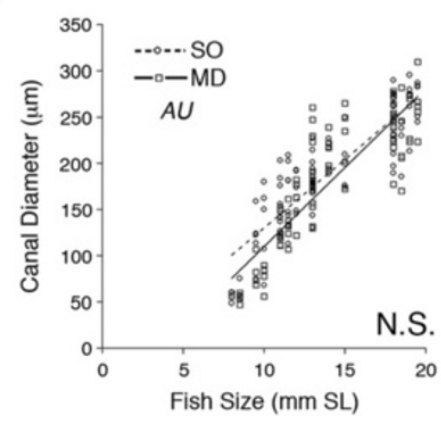

B

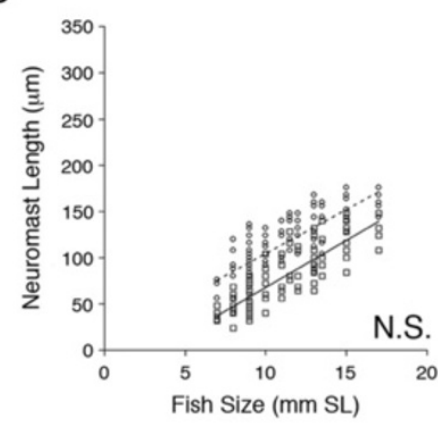

E

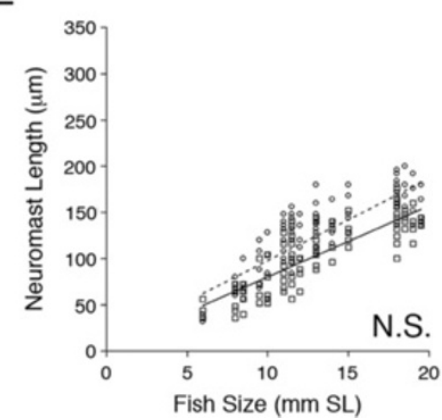

C

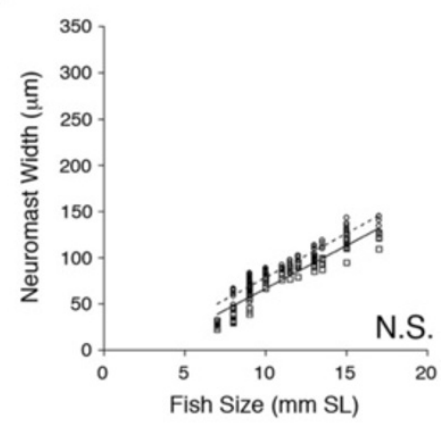

$\mathrm{F}$

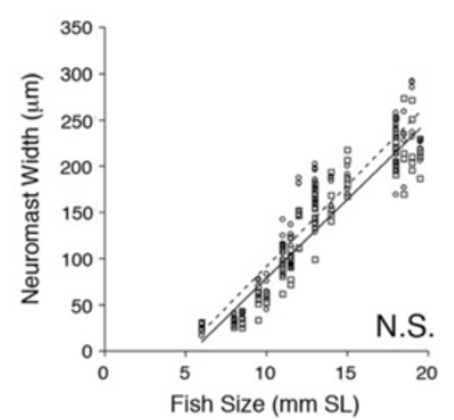

Figure 11 Ontogenetic trends in canal diameter and neuromast size (length, width) in SO and MD canals. A-C) Comparison of rates of increase in three variables: canal diameter (A), neuromast length (B) and neuromast width (C) in Tramitichromis. D-F) Comparison of rates of increase in three variables: canal diameter (D), neuromast length $(\mathbf{E})$ and neuromast width $\mathbf{( F )}$ in Aulonocara derived from histological material. See Tables 2 and 4 for statistical analysis. $P<0.05$ = significant; N.S. = no significant difference in rate of increase in neuromast size between supraorbital (SO) and mandibular (MD) canals.

to selection pressures for changes in sensory function (for example, increased sensitivity to water flows that occurs with an evolutionary change from a narrow to a widened phenotype [34,35]), then the canals (and neuromasts) need to be able to evolve independently of the dermal bones in which they are found. For instance, it has recently been shown that mandibular morphology in Lake Malawi cichlids (Labeotropheus, Metriaclima [76]) can evolve in response to changes in demands on feeding mechanics. This has occurred without a change in the phenotype of the MD lateral line canal (both have narrow canals [47]), but a change in MD canal phenotype (from narrow to widened) has also occurred without substantial changes in mandibular morphology (Metriaclima vs. Aulonocara, [47]). Thus, it appears that the lateral line canals compose a module that is distinct from (and is independent of) the dermatocranial bones in which they are found.

The SO and MD canals are located in the dorsal bones of the skull and in the mandible, respectively. The nasal and frontal bones in which the SO canal is contained are immobile. In stark contrast, the dentary and anguloarticular bones are mobile and play critical roles in prey acquisition and generation of respiratory flow for gill ventilation, and are thus parts of different functional units in the skull (for example, [69]). Local heterochronies were sought out at several levels within each of the two study species: among lateral line canals (SO vs. MD), among canal portions (for example, the SO portions in the nasal vs. frontal bones), and among canal segments (for example, SO 1 to 5). However, local heterochronies were only found among some of the canal segments within a canal, whereas, the two canal portions of the SO and of the MD canals, and the $\mathrm{SO}$ and MD canals themselves did not reveal local heterochronies. It had been predicted that the MD canal would be wider than the SO canal, especially in Aulonocara, given its role in detection of benthic prey [36], but this was not the case. Instead, the SO and MD canals demonstrated the same ontogenetic trajectories (developmental rates), suggesting modular integration, but the SO canal was shown to be consistently wider than the MD canal in each of the two species.

It is concluded that the lateral line canals and portions of lateral line canals contained within different dermal bones are influenced more strongly by their canal identity than by the developmental origins and/or structural and functional demands of the different dermal bone(s) in which they are found. These results confirm findings in another study [47] that showed that canal morphology and dermal bones can evolve independently and support the notion that integration at several levels (canals, canal portions, canal segments) maintains the integrity of the lateral line canal system as a single functional unit (module; [66,77]). 
A

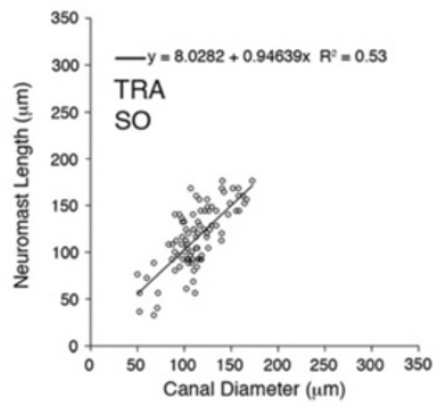

C

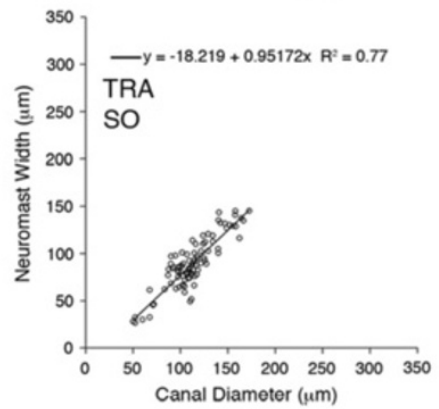

E

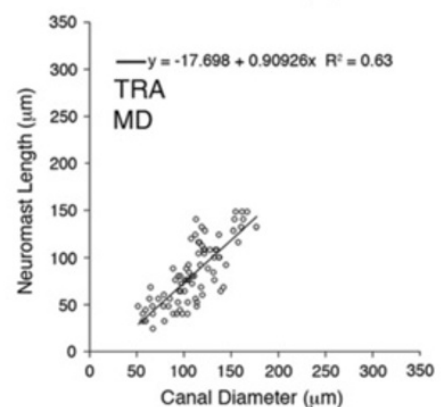

G

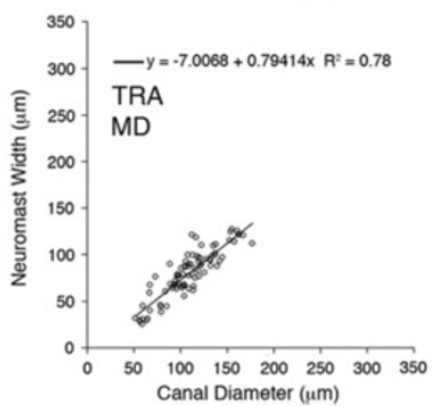

B
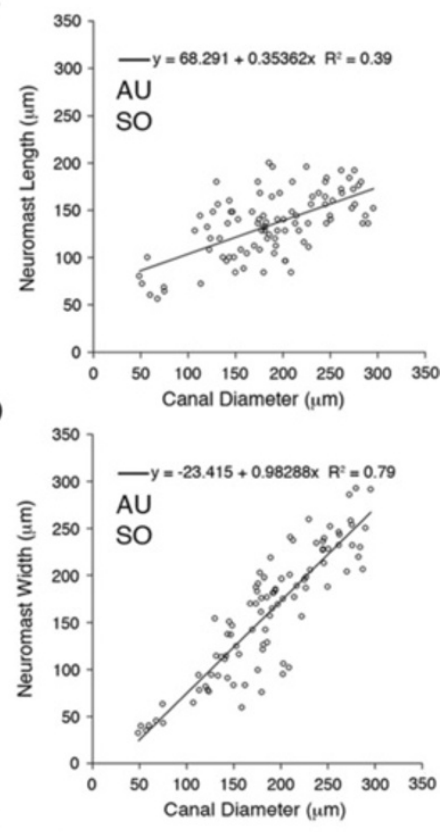

$\mathrm{F}$

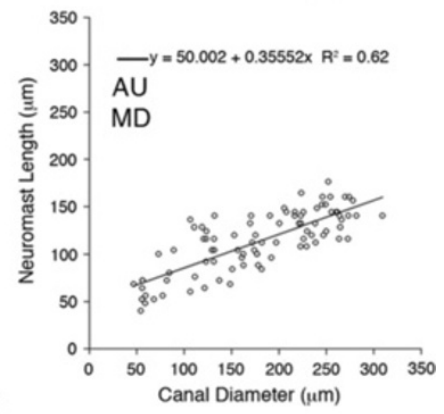

$\mathrm{H}$

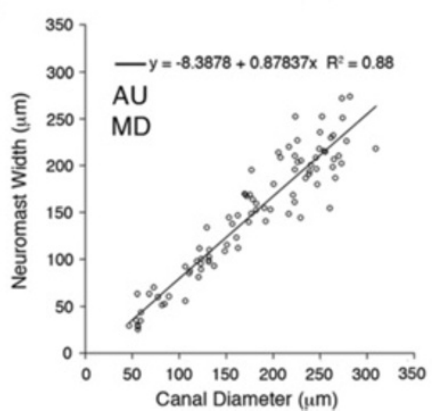

Figure 12 Relationsihp of neuromast size (length and width) and canal diameter in Tramitichromis and Aulonocara. Correlations of neuromast size and canal diameter in the supraorbital $(\mathbf{A}, \mathbf{C})$ and mandibular $(\mathbf{E}, \mathbf{G})$ in Tramitichromis (TRA) and the supraorbital $(\mathbf{B}, \mathbf{D})$ and mandibular $(\mathbf{F}$, H) in Aulonocara (AU). Neuromast length is illustrated in A, E for Tramitichromis and B, F for Aulonocara. Neuromast width is illustrated in $\mathbf{C}, \mathbf{G}$ for Tramitichromis and $\mathbf{D}, \mathbf{H}$ for Aulonocara. In both SO and MD canals, neuromast length appears to increase isometrically with canal diameter in Tramitichromis (A, E), and neuromast length appears to demonstrate a negative allometric trend in Aulonocara (B, F). Neuromast width appears to increase isometrically with canal diameter in the SO and MD canals in Tramitichromis $(\mathbf{C}, \mathbf{G})$ and Aulonocara (D, H). See Table 5 for results of ANOVA's and ACOVA's.

\section{Heterochrony, modularity and the convergent evolution}

\section{of widened canals}

Widened canals have evolved among a small number of diverse families of marine and freshwater fishes [33]. Several groups of mesopelagic (deep-water) marine fishes have generally widened canals (for example, melamphaeids, morids, macrourids; reviewed by [27]), which presumably evolved in response to the need to detect hydrodynamic disturbances in a featureless, three-dimensional environment. In contrast, some benthic feeding freshwater and marine species demonstrate mosaic lateral line phenotypes (narrow and widened phenotypes among different canals in the 
Table 5 Relationship between neuromast size (length, width) and canal diameter in the supraorbital and mandibular canals

\begin{tabular}{lll}
\hline & Tramitichromis & Aulonocara \\
\hline Neuromast length vs. Canal diameter & & $y=0.36 x+57.48 ; R^{2}=0.47$ \\
Combined (SO + MD) & $y=0.97 x-8.54, R^{2}=0.50$ & $y=0.35 x+68.29, R^{2}=0.39$ \\
SO canal & $y=0.95 x+8.0, R^{2}=0.53$ & $y=0.35 x+50.0 ; R^{2}=0.62$ \\
MD canal & $y=0.91 x-17.7, R^{2}=0.63$ & \\
Neuromast width vs. Canal diameter & & $y=0.92 x-14.8, R^{2}=0.83$ \\
Combined (SO + MD) & $y=0.88 x-12.6, R^{2}=0.76$ & $y=0.98 x-23.41, R^{2}=0.79$ \\
SO canal & $y=0.95 x-18.2, R^{2}=0.77$ & $y=0.87 x-8.39, R^{2}=0.88$ \\
MD canal & $y=0.79 x-7.0, R^{2}=0.78$ &
\end{tabular}

Regressions for neuromast length or width (y) versus canal diameter (x), for the supraorbital (SO) and mandibular (MD) canals combined or individually in each species. See also Figure 12.

same individual). Two notable examples are the freshwater cyprinid Notropis buccatus (=Ericymba buccata, silverjaw minnow, [78]) and marine pleuronectid flatfishes of the genus Glyptocephalus (rex sole, witch flounder, [79-81]), both of which are thought to use their lateral line systems to detect benthic invertebrate prey living in sandy substrates, like Aulonocara [36]. In N. buccatus, the dorsal canals (supraorbital, supratemporal) are narrow and the ventral, or ventrally directed canals (mandibular, preopercular, infraorbital) are widened, with unusual, elongate neuromasts that extend across the canal under bony bridges that represent a reduced canal roof [78], not unlike those in zebrafish (Danio rerio [31], unpublished observations). In Glyptocephalus species the canals on the eyed (right, functionally dorsal) side are narrow, but those on the blind (left, functionally ventral) side are

Table 6 Timing and order of canal segment enclosure (Stage III) and ossification (Stage IV)

\begin{tabular}{|c|c|c|c|c|c|}
\hline \multirow[b]{2}{*}{ Species } & \multirow[b]{2}{*}{ Canal neuromast } & \multicolumn{2}{|c|}{ Enclosure (Stage III) } & \multicolumn{2}{|c|}{ Ossification (Stage IV) } \\
\hline & & Mean fish size & Min. canal diameter & Mean fish size & Min. canal diameter \\
\hline Tramitichromis & $\mathrm{SO} 1$ & 13.2 & 83.8 & 17.0 & 137.2 \\
\hline \multirow[t]{9}{*}{ sp. } & $\mathrm{SO} 2$ & 9.8 & 86.7 & 14.0 & 105.8 \\
\hline & $\mathrm{SO} 3$ & 9.2 & 83.7 & 13.3 & 91.0 \\
\hline & $\mathrm{SO} 4$ & 8.3 & 100.4 & 12.0 & 95.9 \\
\hline & $\mathrm{SO} 5$ & 8.4 & 98.0 & 12.1 & 77.9 \\
\hline & MD1 & $-^{*}$ & N/A & $-^{* *}$ & - \\
\hline & MD2 & 13.7 & 102.1 & 17.0 & 116.9 \\
\hline & MD3 & 11.8 & 101.5 & 13.4 & 89.7 \\
\hline & MD4 & 12.4 & 116.2 & 14.3 & 101.4 \\
\hline & MD5 & 14.5 & 130.0 & 15.0 & 149.7 \\
\hline Aulonocara & $\mathrm{SO} 1$ & 17.3 & 186.6 & 18 & 231.4 \\
\hline \multirow[t]{9}{*}{ stuartgranti } & $\mathrm{SO} 2$ & 15.8 & 143.0 & 18.7 & 225.7 \\
\hline & $\mathrm{SO} 3$ & 14.9 & 176.8 & 18.7 & 227.6 \\
\hline & $\mathrm{SO} 4$ & 11.3 & 100.4 & 15.1 & 120 \\
\hline & SO5 & 11.1 & 115.7 & 15.5 & 147.2 \\
\hline & MD1 & 17.3 & 217.8 & $-^{* *}$ & - \\
\hline & MD2 & 15.0 & 113.9 & 19 & 212.8 \\
\hline & MD3 & 16.0 & 112.5 & 17.2 & 206.9 \\
\hline & MD4 & 16.5 & 166.6 & 18.5 & 203.6 \\
\hline & MD5 & 14.4 & 167.2 & 17.7 & 208.2 \\
\hline
\end{tabular}

Mean fish size and minimum canal diameter at which individual canal segments in the supraorbital (SO) and mandibular (MD) canals in Tramitichromis and Aulonocara were enclosed (Stage III) and ossified (Stage IV), as derived from histological material. See Figure 2 for definition of stages. Ascending values of mean fish size at enclosure and ossification among segments within a canal were used to infer the order of canal enclosure and ossification within that canal (see text for additional details). *Not enclosed; **Not ossified. 
A

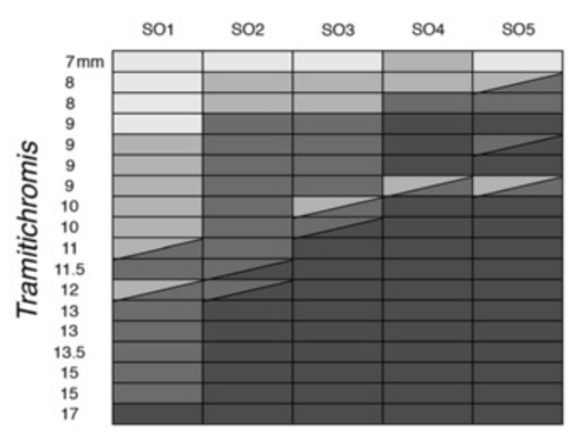

B

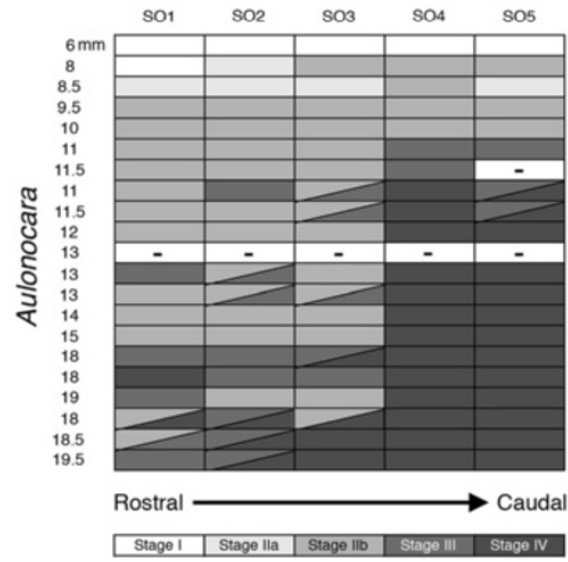

C

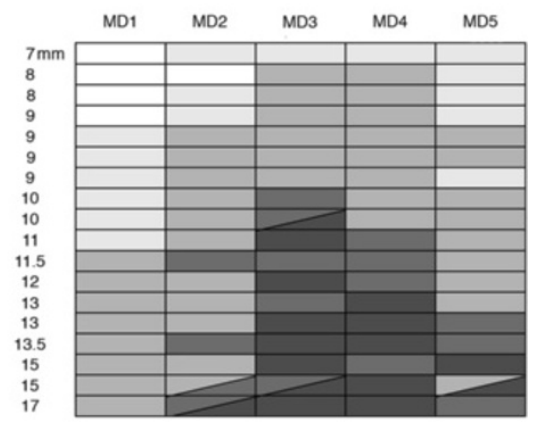

D

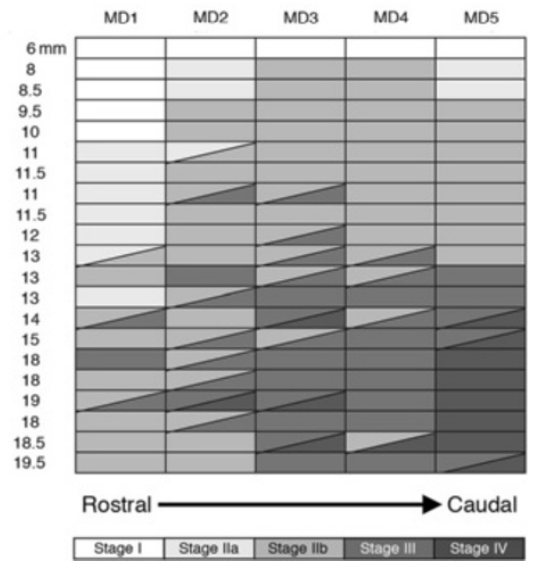

Figure 13 Ontogenetic trends in order and timing of canal segment morphogenesis in SO and MD canals. Staging of the development of each canal segment is illustrated for the supraorbital (SO) canal in Tramitichromis (A), Aulonocara (B), and the mandibular (MD) canal in Tramitichromis (C) and Aulonocara (D) in larvae and juveniles (6 to $19.5 \mathrm{~mm} \mathrm{SL).} \mathrm{Light} \mathrm{to} \mathrm{dark} \mathrm{grays} \mathrm{represent} \mathrm{the} \mathrm{progression} \mathrm{among}$ developmental stages for each canal segment (white = Stage I, darkest gray= Stage IV) on right and left sides, denoted by diagonal lines - see key. Note that in Tramitichromis canal segments become enclosed (Stage III) and ossified (Stage IV) at smaller fish sizes than in Aulonocara in both the SO and MD canals. In both species, the SO canal shows directionality in development (caudal to rostral) and the MD canal shows weak bidirectionality in Tramitichromis only, whereas no pattern was evident in Aulonocara.

widened with large diamond-shaped canal neuromasts [79-81]. Evolution of the widened canals in these fishes is likely the result of natural selection for functional modification of a subset (ventral or left, in N. buccatus and Glyptocephalus species, respectively) of canals via local heterochrony, presumably during the larval stage. In contrast, the overall similarity in morphology among canals and similarity in rates for the $\mathrm{SO}$ (dorsal) and MD (ventral) canals in Aulonocara suggests a resistance to local heterochronic shifts in favor of more global evolutionary changes in lateral line canal morphology. Aulonocara species inhabit a range of depths (to 70 meters) and often live in caves in Lake Malawi $[45,46]$. Widened lateral line canals may have initially evolved for enhanced reception of stimuli associated with, for instance, predator avoidance or social interactions in low light environments, and subsequently took on a role in the detection of benthic prey.

The convergent evolution of widened lateral line canals among diverse fish taxa may have occurred in response to a need for enhanced detection of water flows in different behavioral contexts, and thus in response to different selective pressures. The occurrence of all widened canals in several mesopelagic taxa [27], Aulonocara (this study, [47]) and Eurasian ruffe, Gymnocephalus cernuus [82,83], in contrast to the mosaic canal morphology in other species (N. buccatus, Glyptocephalus) suggests that the modular organization of the lateral line canal system is manifested differently in different taxa. This draws attention to an unappreciated relationship between modularity and both heterochrony and adaptive evolution.

\section{Sensory ontogeny, heterochrony, and the life history of fishes}

The timing of morphogenesis and onset of function in sensory systems is critical in the life history of fishes (discussed by [32]). It follows that evolutionary change in developmental timing will be important for sensory function in the early life history of fishes, and that such insights are important for linking heterochronic change 
to adaptive functional evolution. It has been demonstrated that Tramitichromis are visual feeders that do not depend on the lateral line system (narrow canals) for prey detection [37]. In contrast, Aulonocara use their lateral line system (widened canals) to detect prey, especially in the dark $[36,37]$. The data presented here have shown that the rate of increase in canal diameter is faster, but that morphogenesis of the lateral line canals is somewhat delayed in Aulonocara relative to Tramitichromis. As a result, enclosure and ossification of canal segments occur at larger canal diameters in Aulonocara. For example, in Aulonocara larvae of $15 \mathrm{~mm}$ SL (after the normal time of release from the mother's mouth), the MD canal is already $1.4 \mathrm{x}$ wider than it is in Tramitichromis. Larger diameter canals presumably function at a higher Reynolds Number (Re, the ratio of inertial to viscous forces), which would facilitate displacement of the cupulae (stimulation) of canal neuromasts in response to water movements thus enhancing the probability of prey detection. Evolutionary change in lateral line phenotype accomplished via simple changes in rates of increase in canal diameter and neuromast size and a delay of the onset of canal morphogenesis may be particularly well-suited for the life history of these mouth brooders, in which larvae (with a prolonged yolk-sac stage) reside in the mother's mouth without having to feed for several weeks post-hatch while the lateral line canals start to develop. A comparison of development of narrow and widened canal systems in non-mouth brooders with free living larvae will reveal more about the relationship among developmental processes, early life history strategies and adaptive morphological evolution in the lateral line system.

\section{Conclusions}

The evolution of widened lateral line canals in Aulonocara is the result of dissociated heterochronyacceleration in the rate of increase of both canal diameter and neuromast size, and delay in the onset of canal morphogenesis relative to Tramitichromis. Common rates of increase in canal diameter and neuromast size among canal portions in different dermatocranial bones, among canal segments associated with individual canal neuromasts reflect the absence of local heterochronies and suggest modular integration among canals in both Aulonocara and Tramitichromis. Thus, canal and neuromast morphology are more strongly influenced by their identities as features of the lateral line system than by the attributes of the dermatocranial bones in which the canals are found. Rate heterochrony manifested during the larval stage ensures that the widened canal phenotype in Aulonocara, known to be associated with benthic prey detection in adults, is already present before feeding commences. The lateral line system provides a valuable context for novel analyses of the relationship between developmental processes and the evolution of behaviorally and ecologically relevant phenotypes in fishes.

\section{Additional file}

\begin{abstract}
Additional file 1: Table S1: Summary of differences in canal diameter and neuromast size (length, width) among canals, canal portions in different bones, and canal segments in Tramitichromis and in Aulonocara. "=" denotes no difference in size or rate of increase. Table S2. ANCOVA for canal diameter and neuromast size (length, width) for SO and MD canal portions in two species. See Table S3 for ANOVA results and regressions. Table S3. ANOVA for canal diameter, neuromast size (length, width) in the two portions of the SO and the MD canals. See also Tables S2 and S8. Table S4. ANCOVA for canal diameter for five segments in the $\mathrm{SO}$ and the MD canals in two species. (see text and Table 3 for additional details, and Table S7 for ANOVA). Table S5. ANCOVA for neuromast length for five segments in the SO and the MD canals in two species. (see text and Table 3). See Table S7 for ANOVA results. Table S6. ANCOVA for neuromast width for five segments in the SO and the MD canals in two species. (see text and Table 3 for additional details and Table S7 for ANOVA results). Table S7. ANOVA for canal diameter, neuromast size (length, width) in the five segments of the SO and the MD canals. See Tables S4-6 and S9 for ANCOVAs. Table S9. ANCOVA for canal diameter and neuromast size (length, width) in Tramitichromis and Aulonocara in the five segments of the SO and the MD canals. ANCOVAs were run for all ten comparisons simultaneously. See Table S7 for ANOVA.
\end{abstract}

\section{Abbreviations}

ANCOVA: Analysis of covariance; dpf: Days post-fertilization; IO: Infraorbital canal; L: Liter; MD: Mandibular canal; mm: Millimeters; PO: Preopercular canal; ppt: Parts per thousand; SL: Standard length; SO: Supraorbital canal; $\mu \mathrm{m}$ : Micrometers.

\section{Competing interests}

The authors declare that they have no competing interests.

\section{Authors' contributions}

NCB and JFW designed the study. NCB collected and analyzed the data. NCB wrote the first draft and both authors revised the manuscript, and approved it for final publication.

\section{Acknowledgements}

We thank Edward Baker (Facilities Manager, RI NSF EPSCoR Marine Life Science Facility), Margot Schwalbe, Emily Becker, Lauren Carter, Brandon Fuller, Christopher Holland, Callie Veelenturf, Rebecca Scott and Benjamin Sevey for assistance with fish husbandry. We also thank Christopher Kenaley (Harvard University) for generating $\mu \mathrm{CT}$ data and Benjamin Sevey for generating $\mu \mathrm{CT}$ images. SEM was carried out at the MBL (Woods Hole) and we thank Louis Kerr and his staff for their assistance. Jason Kolbe for statistical expertise. This research was funded by NSF EPSCOR Cooperative Agreements EPS-0554548 and EPS-100405, the College of the Environment and Life Sciences (University of Rhode Island), and NSF grant IOS 0843307 to JFW.

Received: 12 February 2014 Accepted: 14 May 2014

Published: 5 June 2014

\section{References}

1. Gould SJ: Ontogeny and Phylogeny. Cambridge MA: Harvard University Press; 1977.

2. Alberch P, Gould SJ, Oster GF, Wake DB: Size and shape in ontogeny and phylogeny. Paleobiology 1979, 5:296-317.

3. Raff RA, Wray GA: Heterochrony: developmental mechanisms and evolutionary results. J Evol Biol 1989, 2:409-434.

4. McKinney ML: MCNamara KJ: Heterochrony: the evolution of ontogeny. New York: Plenum Press; 1991.

5. Klingenberg CP: Heterochrony and allometry: the analysis of evolutionary change in ontogeny. Biol Rev 1998, 73:79-123.

6. Raff RA: The Shape of Life: Genes, Development, and the Evolution of Animal Form. Chicago: University of Chicago Press; 1996 
7. Schlosser G, Wagner GP: Modularity in Development and Evolution. Chicago: University of Chicago Press; 2004.

8. Mitteroecker P, Gunz P, Weber GW, Bookstein FL: Regional dissociated heterochrony in multivariate analysis. Ann Anat 2004, 186:463-470

9. Smith KK: Heterochrony revisited: the evolution of developmental sequences. Biol J Linn Soc 2001, 73:169-186.

10. Smith KK: Sequence heterochrony and the evolution of development. J Morphol 2002, 252:82-97.

11. Smith KK: Time's arrow: heterochrony and the evolution of development. Int J Dev Biol 2003, 47:613-621.

12. McNamara KJ: Shapes of Time: the Evolution of Growth and Development. Baltimore: The Johns Hopkins University Press; 1997.

13. Gerber S, Hopkins MJ: Mosaic heterochrony and evolutionary modularity: the trilobite genus Zacanthopsis as a case study. Evolution 2011, 65:3241-3252

14. Bemis WE: Paedomorphosis and the evolution of the Dipnoi. Paleobiology 1984, 10:293-307.

15. Boughton DA, Collette BB, McCune AR: Heterochrony in jaw morphology of needlefishes (Teleostei: Belonidae). Syst Zool 1991, 40:329-354.

16. Mabee PM, Olmstead KL, Cubbage CC: An experimental study of intraspecific variation, developmental timing, and heterochrony in fishes. Evolution 2000, 54:2091-2106.

17. Alberch P, Alberch J: Heterochronic mechanisms of morphological diversification and evolutionary change in the neotropical salamander, Bolitoglossa occidentalis (Amphibia: Plethodontidae). J Morphol 1981, 167:249-264.

18. Hanken J: Miniaturization and its effects on cranial morphology in plethodontid salamanders, genus Thorius (Amphibia: Plethodontidae). I. Osteological variation. Biol J Linn Soc 1984, 23:55-75.

19. Schoch R: Heterochrony in the development of the amphibian head. In Evolutionary Change and Heterochrony. Edited by McNamara KJ. Chichester, UK: John Wiley \& Sons Ltd; 1995:107-124.

20. Bhullar B-AS: A phylogenetic approach to ontogeny and heterochrony in the fossil record: cranial evolution and development in anguimorphan lizards. J Exp Zool (Mol Dev Evol) 2012, 318B:521-530.

21. Bhullar B-AS, Marugan-Lobon J, Racimo F, Bever GS, Rowe TB, Norell MA, Abzhanov A: Birds have paedomorphic dinosaur skulls. Nature 2012, 487:223-226.

22. Smith KK: Comparative patterns of craniofacial development in eutherian and metatherian mammals. Evolution 1997, 51:1663-1678.

23. Sanchez-Villagra MR, Goswami A, Weisbecker V, Mock O, Kuratani S: Conserved relative timing of cranial ossification patterns in early mammalian evolution. Evol Dev 2008, 10:519-530.

24. Goswami A: Cranial modularity and sequence heterochrony in mammals. Evol Dev 2007, 9:290-298.

25. Drake AG: Dispelling dog dogma: an investigation of heterochrony in dogs using 3D geometric morphometric analysis of skull shape. Evol Dev 2011, 13:204-213.

26. Koyabu D, Endo H, Mitgutsch C, Suwa G, Catania KC, Zollikofer CPE, Oda S-I, Koyasu K, Ando M, Sanchez-Villagra MR: Heterochrony and developmental modularity of cranial osteogenesis in lipotyphlan mammal. EvoDevo 2011 2:21 [http://www.evodevojournal.com/content/2/1/21]

27. Webb JF: Morphological diversity, development, and evolution of the mechanosensory lateral line system. In The Lateral Line System. Edited by Bleckmann H, Coombs S, Mogdans J. New York: Springer; 2014:17-72.

28. Webb JF: Mechanosensory lateral line: Functional morphology and neuroanatomy. In Handbook of Experimental Animals: The Laboratory Fish. Edited by Ostrander G. London: Academic; 2000:236-244.

29. Tarby ML, Webb JF: Development of the supraorbital and mandibular lateral line canals in the cichlid, Archocentrus nigrofasciatus. J Morphol 2003, 255:44-57.

30. Webb JF, Northcutt RG: Morphology and distribution of pit organs and canal neuromasts in non-teleost bony fishes. Brain Behav Evol 1997, 50:139-151.

31. Webb JF, Shirey JE: Postembryonic development of the cranial lateral line canals and neuromasts in zebrafish. Dev Dyn 2003, 228:370-385.

32. Webb JF: Lateral line morphology and development and implications for the functional ontogeny of flow sensing of fishes. In Flow Sensing in Air and Water - Behavioural, Neural and Engineering Principles of Operation. Edited by Bleckmann H, Mogdans J, Coombs S. New York: Springer; 2014:247-270

33. Webb JF: Gross morphology and evolution of the mechanoreceptive lateral-line system in teleost fishes. Brain Behav Evol 1989, 33:34-53.
34. Denton EJ, Gray JAB: Mechanical factors in the excitation of the lateral lines of fishes. In Sensory Biology of Aquatic Animals. Edited by Atema J, Fay RR, Popper AN, Tavolga WN. New York: Springer; 1988:595-618.

35. Denton EJ, Gray JAB: Some observations on the forces acting on neuromasts in fish lateral line canals. In The Mechanosensory Lateral Line: Neurobiology and Evolution. Edited by Coombs S, Görner P, Münz H. New York: Springer; 1989:79-97.

36. Schwalbe MAB, Bassett DK, Webb JF: Feeding in the dark: lateral-linemediated prey detection in the peacock cichlid Aulonocara stuartgranti. J Exp Biol 2012, 21:2060-2071.

37. Schwalbe MAB, Webb JF: Sensory basis for detection of benthic prey in two Lake Malawi cichlids. Zoology (Jena) 2014, 117:112-121.

38. Webb JF: Developmental constraints and evolution of the lateral line system in teleost fishes. In The Mechanosensory Lateral Line - Neurobiology and Evolution. Edited by Coombs S, Gorner P, Munz H. New York: Springer; 1989:79-98.

39. Fryer G, Iles TD: The Cichlid Fishes of the Great Lakes of Africa: Their Biology and Evolution. Oliver and Boyd: Edinburgh; 1972.

40. Greenwood PH: The Haplochromine Fishes of the East African Lakes. Ithaca NY: Cornell University Press; 1981.

41. Trewavas E: Tilapiine Fishes of the Genera Sarotherodon, Oreochromis, and Danakilia. London: British Museum (Natural History); 1983.

42. Branson BA: The lateral-line system in the Rio Grande perch, Cichlasoma cyanoguttatum (Baird and Girard). Am Midl Nat 1961, 65:446-458.

43. Peters HM: Anatomie und entwicklungsgeschichte des lateralissystems von Tilapia (Pisces, Cichlidae). Z Morphol Tiere 1973, 74:89-161.

44. Webb JF: Neuromast morphology and lateral line trunk ontogeny in two species of cichlids: an SEM study. J Morphol 1989, 202:53-68.

45. Konings A: Ad Koning's Book of Cichilds and Other Fishes of Lake Malawi. Neptune City, NJ: TFH Publications; 1990.

46. Konings A: Malawi Cichlids in their Natural Habitat. 4th edition. El Paso, TX: Cichlid Press; 2007.

47. Webb JF, Bird NC, Carter L, Dickson J: Comparative development and evolution of two lateral line phenotypes in Lake Malawi cichlids. J Morphol 2014, 275:678-692.

48. Schwalbe MAB, Webb JF: The effect of light intensity on prey detection behavior in two Lake Malawi cichlids, Aulonocara stuartgranti and Tramitichromis sp. J Comp Physiol A, in press.

49. Hall BK: The role of movement and tissue interactions in the development and growth of bone and secondary cartilage in the clavicle of the embryonic chick. J Embryol Exp Morph 1986, 93:133-152.

50. Potthoff T, Moser HG, Richards WJ, Cohen DM, Fahay MP, Kendall AW Jr, Richardson SL, Lawrence KS: Clearing and staining technique. In Ontogeny and Systematics of Fishes. American Society of Ichthyologists and Herpetologists Special Publication No. 1. Lawrence, KS: Allen Press Inc; 1984:35-37.

51. Johnson PO, Neyman J: Tests of certain linear hypotheses and their application to some educational problems. Stat Res Mem 1936, 1:57-93.

52. White CR: Allometric analysis beyond heterogeneous regression slopes: use of the Johnson-Neyman technique in comparative biology. Physiol Biochem Zool 2003, 76:135-140.

53. Klingenberg CP, Mebus K, Auffray J-C: Developmental integration in a complex morphological structure: how distinct are the modules in the mouse mandible? Evol Dev 2003, 5:522-531.

54. Klingenberg CP: Morphological integration and developmental modularity. Ann Rev Ecol Evol Syst 2008, 39:115-132.

55. Klingenberg CP: Evolution and development of shape: integrating quantitative approaches. Nat Rev Genet 2010, 11:623-635.

56. Raff EC, Raff RA: Dissociability, modularity, evolvability. Evol Dev 2000, 2:235-237.

57. Polly PD, Head JJ, Cohn MJ: Testing modularity and dissociation: the evolution of regional proportions in snakes. In Beyond Heterochrony: the Evolution of Development. Edited by Zelditch ML. New York: Wiley-Liss, Inc; 2001:305-335.

58. Becker EA: The distribution and ontogeny of neuromast receptor organs and a comparison of methods for chemical ablation of the lateral line system in two cichlid fishes. Master's thesis: University of Rhode Island, Department of Biological Sciences; 2013.

59. Montgomery JC, Bleckmann H, Coombs S: Sensory ecology and neuroethology of the lateral line. In The Lateral Line System. Edited by Coombs S, Bleckmann H, Fay RR, Popper AN. New York: Springer; 2014:121-150. 
60. DeBeer GR: The Development of the Vertebrate Skull. Chicago: University of Chicago Press; 1985.

61. Graham-Smith W: On the lateral lines and dermal bones in the parietal region of some crossopterygian and dipnoan fishes. Phil Trans $R$ Soc Lond 1978, 282:41-105.

62. Patterson C: Cartilage bones, dermal bones and membrane bones, or the exoskeleton versus the endoskeleton. In Problems in Vertebrate Evolution. Edited by Andrews SM, Miles RS, Walker AD. New York: Academic; 1977:77-121.

63. Schaeffer B: The dermal skeleton of fishes. In Problems in Vertebrate Evolution. Edited by Andrews SM, Miles RS, Walker AD. New York: Academic; 1977:25-52.

64. Atchley WR, Hall BK: A model for development and evolution of complex morphological structures. Biol Rev 1991, 66:101-157.

65. Schlosser G: The role of modules in development and evolution. In Modularity in Development and Evolution. Edited by Schlosser G, Wagner GP. Chicago: The University of Chicago Press; 2004:519-582.

66. Goswami A, Weisbecker V, Sanchez-Villagra MR: Developmental modularity and the marsupial-placental dichotomy. J Exp Zool (Mol Dev Evol) 2009, 312B:186-195.

67. Koyabu D, Werneburg I, Morimoto N, Zollikofer CP, Forasiepi AM, Endo H, Kimura J, Ohdachi SD, Truong Son N, Sánchez-Villagra MR: Mammalian skull heterochrony reveals modular evolution and a link between cranial development and brain size. Nat Commun 2014, 5:3625

68. McNamara KJ: Heterochrony: the evolution of development. Evol Edu Outreach 2012, 5:203-218.

69. Hulsey CD, Fraser GJ, Streelman JT: Evolution and development of complex biomechanical systems: $\mathbf{3 0 0}$ million years of fish jaws. Zebrafish 2005, 2:243-257.

70. Asaoka A, Nakae M, Sasaki K: Innervation of the lateral line system in Rhyacichthys aspro: the origin of superficial neuromast rows in gobiods (Perciformes: Rhyacichthyidae). Icthyol Res 2014, 61:49-58.

71. Gregory WK: Fish skulls: a study of the evolution of natural mechanisms. Trans Am Phil Soc 1933, 23. i-vii+75-481.

72. Monteiro LR, Bonato V, dos Reis SF: Evolutionary integration and morphological diversification in complex morphological structures: mandible shape divergence in spiny rats (Rodentia, Echimyidae). Evol Dev 2005, 7:429-439.

73. Zelditch ML, Wood AR, Bonett RM, Swiderski DL: Modularity of the rodent mandible: integrating bones, muscles, and teeth. Evol Dev 2008 , 10:756-768.

74. Kague E, Gallagher M, Burke S, Parsons M, Franz-Odendaal T, Fisher S: Skeletogenic fate of zebrafish cranial and trunk neural crest. PLOS ONE 2012, 7:e47394

75. Fujimura K, Okada N: Bone development in the jaw of Nile tilapia Oreochromis niloticus (Pisces: Cichlidae). Dev Growth Differ 2008, 50:339-355.

76. Parsons KJ, Marquez E, Albertson RC: Constraint and opportunity: the genetic basis and evolution of modularity in the cichlid mandible. Am Nat 2012, 179:64-78

77. Wagner GP: Homologues, natural kinds and the evolution of modularity. Am Zool 1996, 36:36-43.

78. Reno HW: The lateral-line system of the silverjaw minnow, Ericymba buccata Cope. Southwest Nat 1971, 15:347-358.

79. McDonnell R: On the system of the "lateral line" in fishes. Trans R Irish Acad Sci 1871, 24:161-188.

80. Sakamoto K: Interrelationships of the family Pleuronectidae (Pisces: Pleuronectiformes). Mem Fac Fish, Hokkaido Univ 1984, 31:95-215.

81. Webb JF: Lateral Line Structure. In Encyclopedia of Fish Physiology: from Genome to Environment, Volume 1. Edited by Farrell AP. San Diego: Academic; 2011:336-346.

82. Disler NN: Lateral Line Sense Organs and their Importance in Fish Behavior. Israel Program for Scientific Translations: Jerusalem; 1971.

83. Curčić-Blake B, van Netten SM: Source location encoding in the fish lateral line canal. J Exp Biol 2006, 209:1548-1559.

doi:10.1186/2041-9139-5-21

Cite this article as: Bird and Webb: Heterochrony, modularity, and the functional evolution of the mechanosensory lateral line canal system of fishes. EvoDevo 2014 5:21

\section{Submit your next manuscript to BioMed Central and take full advantage of:}

- Convenient online submission

- Thorough peer review

- No space constraints or color figure charges

- Immediate publication on acceptance

- Inclusion in PubMed, CAS, Scopus and Google Scholar

- Research which is freely available for redistribution 